\title{
Nanoscale imaging of rat atrial myocytes by scanning ion conductance microscopy reveals heterogeneity of T-tubule openings and ultrastructure of the cell membrane
}

\author{
Sun Hwa Park ${ }^{1, \#}$, Ami Kim ${ }^{1, \#}$, Jieun An ${ }^{1, \#}$, Hyun Sung Cho ${ }^{2}$, and Tong Mook Kang ${ }^{1, *}$ \\ ${ }^{1}$ Department of Physiology, Samsung Medical Center, Sungkyunkwan University School of Medicine, Suwon 16419, ${ }^{2}$ Department of Anesthesiology and Pain \\ Medicine, Samsung Medical Center, Sungkyunkwan University School of Medicine, Seoul 06351, Korea
}

\section{ARTICLE INFO \\ Received September 29, 2020 \\ Revised October 5, 2020 \\ Accepted October 5, 2020 \\ *Correspondence \\ Tong Mook Kang \\ E-mail: tongmkang@skku.edu}

Key Words

Atrium

Rat

Scanning ion conductance microscopy Transverse tubule

\#These authors contributed equally to this work.

\begin{abstract}
In contrast to ventricular myocytes, the structural and functional importance of atrial transverse tubules (T-tubules) is not fully understood. Therefore, we investigated the ultrastructure of T-tubules of living rat atrial myocytes in comparison with ventricular myocytes. Nanoscale cell surface imaging by scanning ion conductance microscopy (SICM) was accompanied by confocal imaging of intracellular T-tubule network, and the effect of removal of T-tubules on atrial excitation-contraction coupling (EC-coupling) was observed. By SICM imaging, we classified atrial cell surface into 4 subtypes. About $38 \%$ of atrial myocytes had smooth cell surface with no clear T-tubule openings and intracellular T-tubules (smooth-type). In $33 \%$ of cells, we found a novel membrane nanostructure running in the direction of cell length and named it 'longitudinal fissures' (LFs-type). Interestingly, T-tubule openings were often found inside the LFs. About $17 \%$ of atrial cells resembled ventricular myocytes, but they had smaller T-tubule openings and a lower Z-groove ratio than the ventricle (ventricular-type). The remaining $12 \%$ of cells showed a mixed structure of each subtype (mixed-type). The LFs-, ventricular-, and mixed-type had an appreciable amount of reticular form of intracellular T-tubules. Formamide-induced detubulation effectively removed atrial T-tubules, which was confirmed by both confocal images and decreased cell capacitance. However, the LFs remained intact after detubulation. Detubulation reduced action potential duration and L-type $\mathrm{Ca}^{2+}$ channel (LTCC) density, and prolonged relaxation time of the myocytes. Taken together, we observed heterogeneity of rat atrial T-tubules and membranous ultrastructure, and the alteration of atrial EC-coupling by disruption of T-tubules.
\end{abstract}

\section{INTRODUCTION}

The transverse tubules (T-tubules) of the cardiomyocytes are perpendicular invaginations of the plasma membrane that regularly positioned on the Z-lines. As the T-tubule membranes contain multiple ion channels and transporters, such as L-type $\mathrm{Ca}^{2+}$ channel (LTCC) and $\mathrm{Na}^{+} / \mathrm{Ca}^{2+}$ exchanger (NCX), the abundance and organization of T-tubules determine action potential dura- tion (APD) and consequent $\mathrm{Ca}^{2+}$ signaling patterns. Therefore, $\mathrm{T}$ tubule is a key structural element for efficient cardiac excitationcontraction coupling (EC-coupling). Ventricular cardiomyocytes have well-organized T-tubules that convey sarcolemmal action potential (AP) throughout the cell interior and produce global $\mathrm{Ca}^{2+}$ transient and muscle contraction [1]. At the junctions of the T-tubule membrane and the sarcoplasmic reticulum (SR) membrane, functional coupling between LTCC and ryanodine recep-

\section{(C) (i) (s)}

This is an Open Access article distributed under the terms of the Creative Commons Attribution Non-Commercial License, which permits unrestricted non-commercial use, distribution, and reproduction in any medium, provided the original work is properly cited. Copyright $\odot$ Korean J Physiol Pharmacol, pISSN 1226-4512, elSSN 2093-3827
Author contributions: S.H.P., A.K., and J.A. performed imaging and electrophysiology experiments, and analyzed data and revised manuscript. H.S.C. and T.M.K. conceptualized and designed the study, and wrote and revised manuscript. 
tor $\mathrm{Ca}^{2+}$ release channels (RyRs) produces synchronized $\mathrm{Ca}^{2+}$-induced $\mathrm{Ca}^{2+}$ release that causes myofilament contraction [2]. Also, this spatial coupling between the T-tubule and the SR is critical for diastolic $\mathrm{Ca}^{2+}$ extrusion. The higher expression of NCX on the T-tubule membrane and abundant expression of $\mathrm{SR} \mathrm{Ca}^{2+}$-ATPase (SERCA) close to the T-tubules support efficient $\mathrm{Ca}^{2+}$ extrusion and sequestration during diastole [3]. As a consequence, not only the degree of T-tubule development but also its structural integrity determines the spatiotemporal synchronization of $\mathrm{Ca}^{2+}$ transient that gives efficient EC-coupling. It is quite noteworthy that disrupted T-tubules were often found in diseased hearts such as heart failure, cardiac hypertrophy, and ischemic heart disease [46].

It has long been thought that atrial myocyte lacked the T-tubule system. As a consequence, the absence of T-tubules does not guarantee a rapid and homogenous intracellular $\mathrm{Ca}^{2+}$ transient that produces a sub-maximal systolic force. Therefore, atrial ECcoupling and related $\mathrm{Ca}^{2+}$ signaling have often been explained by the mechanism of centripetal $\mathrm{Ca}^{2+}$ wave [7]. In atrial myocytes with no T-tubule system, a systolic $\mathrm{Ca}^{2+}$ transient that initiates at the cell periphery propagates toward the deep area of the myocyte as a centripetal $\mathrm{Ca}^{2+}$ wave [7-9]. However, recent investigations have suggested that atrial myocytes preserve some T-tubules with a great diversity in morphology and abundance [10]. It is suggested that the larger the animals, the higher the T-tubule expression. Relatively well-organized T-tubules were found in humans or sheep atria, but rudimentary T-tubules were observed in the atria of small laboratory animals such as rats and mice [11,12]. Therefore, it is difficult to estimate accurately the contribution of T-tubules on atrial EC-coupling because of its sparsity, structural diversity, cell to cell variation, and interspecies difference. Furthermore, it is quite difficult to evaluate the pathological consequences of partially destroyed T-tubules in diseased atria.

Confocal microscopic imaging of the living cardiomyocytes stained with lipophilic membrane dye (di-8-ANEPPS) has been widely used to visualize intracellularly oriented T-tubule network $[13,14]$. Additional immunostaining of the fixed cells against Ttubule specific proteins (caveolin-3 or dihydropyridine receptors) revealed further the 3-dimensional distribution of intracellular Ttubules [14]. Although these classical T-tubule staining techniques are advantageous for visualization of the internal architecture of the T-tubule network [5], it cannot reveal nanometers-sized Ttubule openings or orifices on the cell surface, especially in living cardiomyocytes. When the T-tubules are stained in ventricular myocytes it is relatively easy to figure out the surface T-tubule openings, because ventricular T-tubules invaginate perpendicular to the surface membrane and striated at a regular interval along the Z-lines. However, visualization of the surface T-tubule openings from atrial myocytes is very difficult because of the rudimentary, heterogeneous, and amorphous architecture of the Ttubule system.

Therefore, the present study aimed to visualize the cell surface
T-tubule openings at a nanometer resolution scale in isolated living atrial myocytes. To the purpose we used a newly developed nanoimaging technique, scanning ion conductance microscopy (SICM), which is a modified scanning probe microscopy (SPM) technique [15]. In general, SPM is a microscopic imaging technique that scans a probing tip over a sample surface to give the physical profiles of the sample at a nanometer-scale resolution. Although various SPM technologies including atomic force microscopy have been developed, there are many difficulties with its application to the live cells in physiological conditions $[16,17]$. SICM is a modified SPM technique that permits noninvasive topographical imaging of live cell membrane at several tens of nanometers resolution [15]. As a scanning probe, SICM uses a vertically positioned glass nanopipette with a tip diameter of $<$ $100 \mathrm{~nm}$ that filled with conducting salt solutions [18].

By SICM imaging of the atrial cell surface, confocal imaging of the di-8-ANEPPS stained intracellular T-tubules, patch-clamp electrophysiology, and myocyte contraction measurement, we aimed to understand (i) the structural features of surface T-tubule openings and membrane nanostructures, (ii) the architecture of intracellular T-tubule network, (iii) relationship between the Ttubule network and surface structure, and (iv) the consequences of detubulation on the T-tubules and EC-coupling of the rat atrial myocytes.

\section{METHODS}

\section{Isolation of rat cardiomyocytes}

The use of animals and all procedures were approved by the Institutional Animal Care and Use Committee (IACUC) at Sungkyunkwan University, Korea (approval No. SKKUIACUC2018-04-08-3). Cardiomyocytes were isolated from male Sprague-Dawley (SD) rats of 8-10 weeks old. The rats were anesthetized in a $\mathrm{CO}_{2}$ chamber and then sacrificed by cervical dislocation. The heart was quickly removed and mounted on a Langendorff perfusion apparatus. To keep the heartbeat and clear the coronary circulation, retrograde perfusion was processed at $37^{\circ} \mathrm{C}$ with a $\mathrm{Ca}^{2+}$-containing Tyrode solution containing (in mM) $141.4 \mathrm{NaCl}, 4 \mathrm{KCl}, 0.33 \mathrm{NaH}_{2} \mathrm{PO}_{4}, 5.5$ glucose, $1.8 \mathrm{CaCl}_{2}$, $1 \mathrm{MgCl}_{2}, 14.5 \mathrm{D}$-mannitol, 10 HEPES, pH adjusted at 7.4 with $\mathrm{NaOH}$. Then, the heart was perfused further for 6 min with $\mathrm{Ca}^{2+}$ free Tyrode solution containing (in $\mathrm{mM}$ ) $135 \mathrm{NaCl}, 5.4 \mathrm{KCl}, 5$ HEPES, $0.4 \mathrm{Na}_{2} \mathrm{HPO}_{4} \cdot 12 \mathrm{H}_{2} \mathrm{O}, 20$ taurine, $3.5 \mathrm{MgCl}_{2}, 5$ glucose, $\mathrm{pH}$ adjusted at 7.4 with $\mathrm{NaOH}$. After that, the heart was perfused with a $\mathrm{Ca}^{2+}$-free digestion solution containing collagenase type II (Worthington, Lakewood, CA, USA) $1 \mathrm{mg} / \mathrm{ml}$, protease (SigmaAldrich, St. Louis, MO, USA) $1 \mathrm{mg} / \mathrm{ml}, 0.2 \%$ bovine serum albumin (BSA; Sigma-Aldrich), $\mathrm{CaCl}_{2} 0.05 \mathrm{mM}$ for $8 \mathrm{~min}$ at $37^{\circ} \mathrm{C}$. Both atria were carefully excised from the heart, chopped, and gently shaken at $37^{\circ} \mathrm{C}$ in a solution containing collagenase type 
II (Worthington) $1 \mathrm{mg} / \mathrm{ml}, 0.2 \% \mathrm{BSA}, \mathrm{CaCl}_{2} 0.05 \mathrm{mM}$. Isolated myocytes were washed by $1 \% \mathrm{BSA}$ and kept in $\mathrm{Ca}^{2+}$-free storage solution containing (in mM) $120 \mathrm{NaCl}, 5.4 \mathrm{KCl}, 5 \mathrm{MgSO}_{4} \cdot 7 \mathrm{H}_{2} \mathrm{O}, 5$ sodium pyruvate, 5.5 glucose, 20 taurine, 10 HEPES, 29 D-mannitol, $\mathrm{pH} 7.4$ with $\mathrm{NaOH}$. The same digestion protocol was used for the isolation of ventricular myocytes. The cardiomyocytes were used for experiments within $6 \mathrm{~h}$ of the isolation.

\section{Scanning ion conductance microscopy}

We used a SICM device (XE-Bio; Park Systems, Suwon, Korea) consisted of a glass nanopipette, an $\mathrm{X}-\mathrm{Y}$ scanner, a Z-axis piezo driver, a current amplifier, a feedback controller, an inverted microscope, and a data acquisition system. Isolated cardiomyocytes were placed in a $35-\mathrm{mm}$ culture dish containing $\mathrm{Ca}^{2+}$-free storage solution, and SICM imaging was conducted at room temperature $\left(\sim 25^{\circ} \mathrm{C}\right)$. Imaging of the cell surface was operated under the ARSmode (Park Systems) or hopping-mode of SICM $[19,20]$. The probing nanopipette was fabricated with $1.0 \mathrm{~mm}$ outer diameter and $0.58 \mathrm{~mm}$ inner diameter borosilicate glass tubing (Warner Instrument, Hamden, CT, USA) using a laser puller P-2000 (Sutter Instrument, Novato, CA, USA). In all experiments, measured nanopipette resistance was $\sim 150 \mathrm{M} \Omega$ when it was filled with a $\mathrm{Ca}^{2+}$-free cell storage solution. The scan size was measured differently for each cell with a randomly selected area. The scanning pixel was 128 (X-axis) by 128 (Y-axis). The cells were imaged with the XEP software program (ver. 1.7.94 build 9; Parks Systems), and the acquired topographic images were analyzed with the XEI analysis program (ver. 1.8.0 build 20; Park Systems).

\section{Confocal imaging of the intracellular T-tubules with di-8-ANEPPS staining}

The cardiomyocytes were incubated with $5 \mu \mathrm{M}$ di-8-ANEPPS, a membrane fluorescent dye (Sigma-Aldrich), for $5 \mathrm{~min}$ at room temperature and immediately washed twice with cell storage solution. All image acquisition was completed on confocal laser microscopy (Zeiss LSM-710; Zeiss, Oberkochen, Germany) by using $488 \mathrm{~nm}$ excitation light with detection at $>505 \mathrm{~nm}$. Z-stack images were recorded with the same $X-Y$ pixel (1024 by 1024) size and a z-step of $0.5 \mu \mathrm{m}$ intervals.

\section{Formamide-induced detubulation protocol}

For detubulation (an acute removal of T-tubules), the cardiomyocytes were bathed in a control bath solution containing (in mM) $113 \mathrm{NaCl}, 5 \mathrm{KCl}, 1 \mathrm{MgSO}_{2}, 1 \mathrm{CaCl}_{2}, 1 \mathrm{Na}_{2} \mathrm{HPO}_{4}, 20$ sodium acetate, 10 glucose, $5 \mathrm{U} / \mathrm{L}$ insulin, $\mathrm{pH} 7.4$ with $\mathrm{NaOH}$. Then, the myocytes were treated with $1.5 \mathrm{M}$ of formamide (Sigma-Aldrich) for $15 \mathrm{~min}$ at room temperature and washed with a control bath solution to induce detubulation [21].

\section{Analysis of the line profiles with Fast Fourier transformation (FFT)}

The line profiles obtained from the SICM images and confocal images were analyzed with a FFT algorithm to retrieve regular organization or positioning of the T-tubules or Z-grooves. The power spectrum of the desired line profile was extracted from 2D topographic SICM images by the XEI analysis program (Park Systems). The line profiles and power spectrums of the confocal images were analyzed with the Zen 2011 program (Zeiss). From the retrieved power spectrum peaks, we determined the regularly repeating appearance of T-tubules or Z-grooves. The FFT analysis was used to evaluate the presence of $\mathrm{T}$-tubules and its remodeling before and after the formamide-induced detubulation protocol [5].

\section{Whole-cell patch-clamp recording}

Cell membrane capacitance $\left(\mathrm{C}_{\mathrm{m}}\right)$ and LTCC were recorded by conventional whole-cell patch-clamp configuration, and APs were measured by nystatin $(0.2 \mathrm{mg} / \mathrm{ml}$, dissolved in DMSO; Glentham, Edinburgh, UK)-perforated configuration at RT. Atrial myocytes were placed on a recording chamber mounted on an inverted microscope (IX-70; Olympus, Tokyo, Japan). Patch pipettes were pulled from borosilicate glass tubing (\#1B150F-4; WPI, Sarasota, FL, USA) with a vertical puller (PP-830, Narashige, Tokyo, Japan) to give 2-3 $\mathrm{M} \Omega$ tip resistance when filled with internal pipette solutions. Pipette capacitance and series resistance were compensated up to $>70 \%$. Cell membrane capacitance was measured by integrating the capacitance current activated by $10 \mathrm{mV}$ hyperpolarizing pulse from a holding potential of $-80 \mathrm{mV}$. Atrial APs were recorded by nystatin-perforated patches. The APs were elicited by injecting a current of $>300 \mathrm{pA}$ for $4 \mathrm{~ms}$ while pacing at 1 or $2 \mathrm{~Hz}$ frequency. To evoke APs, the membrane potentials were set at $-70 \mathrm{mV}$. Obtained results were analyzed by measuring duration at 20,50 , and $90 \%$ repolarization, i.e., $\mathrm{APD}_{20}, \mathrm{APD}_{50}$, and $\mathrm{APD}_{90}$, respectively. For LTCC recording, cells were clamped at holding potential of $-80 \mathrm{mV}$, and LTCC was recorded by applying $150 \mathrm{~ms}$ step pulses (from -50 to $+40 \mathrm{mV},+10 \mathrm{mV}$ increments; 5 sec inter-pulse intervals) with $50 \mathrm{~ms}$ pre-pulse at $-40 \mathrm{mV}$ to inactivate sodium and T-type $\mathrm{Ca}^{2+}$ currents. LTCC currents were normalized to measured cell capacitances $(\mathrm{pA} / \mathrm{pF})$ and current density-voltage relationship (I-V) curves were constructed. Patch-clamp recordings were acquired by a patch-clamp amplifier (Axopatch-1D; Axon Instruments, Foster City, CA, USA) and pClamp software 7.0 (Axon Instruments). Recorded traces were analyzed by Origin 6.1 software (Microcal Inc, Northampton, MA, USA).

\section{Myocyte contraction experiment}

Shortenings of sarcomere length (SL) were measured by a video-sarcomere detection system (IonOptix Corp., Milton, 
MA, USA). Atrial myocytes were placed in a temperature $\left(35^{\circ} \mathrm{C}\right)$ controlled chamber set on the stage of an inverted microscope (CKX41; Olympus). Atrial myocytes were paced by electric field stimulation (EFS) at a stimulation frequency of 0.2 to $4 \mathrm{~Hz}$, and SL shortenings were recorded in real-time and analyzed using IonWizard software (IonOptix).

\section{Solutions and chemicals}

Standard normal Tyrode bath solution for recordings of APs contained (in $\mathrm{mM}$ ) $140 \mathrm{NaCl}, 5.4 \mathrm{KCl}, 5$ HEPES, 10 glucose, 1 $\mathrm{MgCl}_{2}$ and $1.8 \mathrm{CaCl}_{2}$ (pH 7.4 with $\mathrm{NaOH}$ ). Nystatin $(0.2 \mathrm{mg} / \mathrm{ml}$, dissolved in DMSO; Glentham) perforated patch pipettes were back-filled with solution contained (in $\mathrm{mM}$ ) $140 \mathrm{KCl}, 10 \mathrm{HEPES}$, $1 \mathrm{MgCl}_{2}$ and 5 EGTA, (pH 7.2 with $\mathrm{KOH}$ ). Bath solution for LTCC recording contained (in $\mathrm{mM}$ ) $140 \mathrm{NaCl}, 5 \mathrm{KCl}, 5 \mathrm{CsCl}, 0.33$ $\mathrm{NaH}_{2} \mathrm{PO}_{4}, 5$ HEPES, 10 glucose, $0.5 \mathrm{MgCl}_{2}$ and $1.8 \mathrm{CaCl}_{2}(\mathrm{pH} 7.4$ with $\mathrm{NaOH}$ ). Pipette solution for LTCC recordings contained (in mM) 135 Cs-aspartate, $10 \mathrm{NaCl}, 5 \mathrm{Mg}^{2+}$-ATP, 10 EGTA and 10 HEPES (pH 7.2 with CsOH). Normal Tyrode solution used for myocyte contraction experiment contained (in $\mathrm{mM}$ ) $141.4 \mathrm{NaCl}$, $4 \mathrm{KCl}, 10 \mathrm{HEPES}, 5.5$ glucose, $0.33 \mathrm{NaH}_{2} \mathrm{PO}_{4}, 1 \mathrm{MgCl}_{2}$ and 1.8 $\mathrm{CaCl}_{2}(\mathrm{pH} 7.4$ with $\mathrm{NaOH})$.

\section{Statistics}

Data analysis was performed with Origin software (version 6.1., OriginLab, Northampton, MA, USA). Results were shown as mean \pm standard error of the mean with sample numbers. Statistical significance was calculated by paired or unpaired Student's $\mathrm{t}$-tests and significance was set at $\mathrm{p}<0.05$.
A

\section{Control}
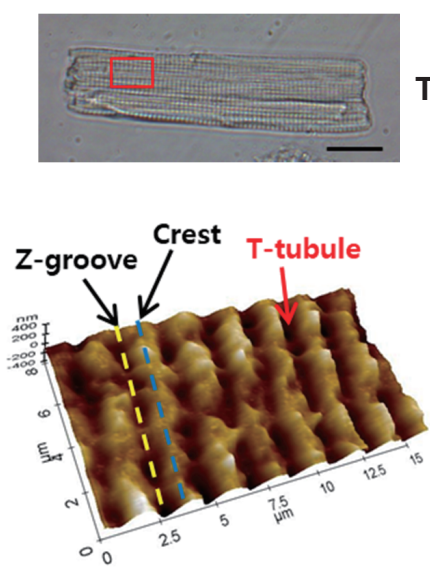

(iii)
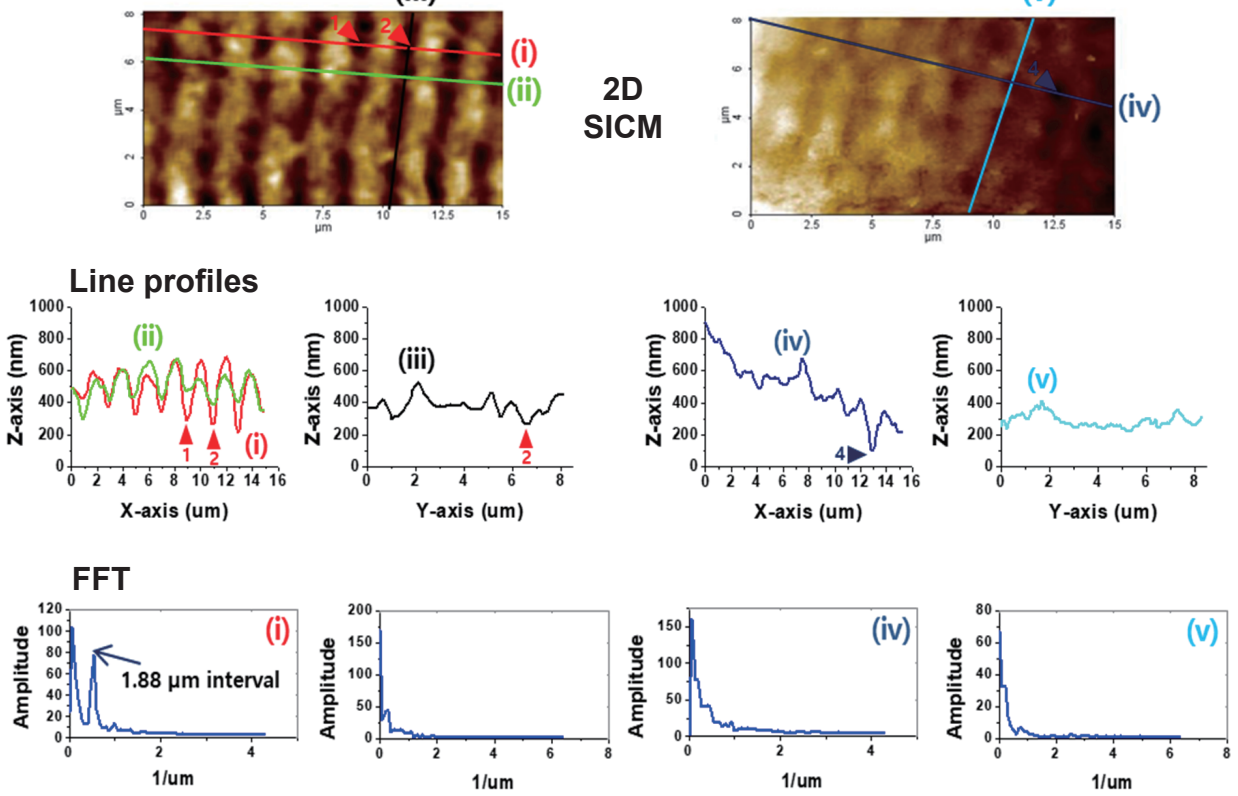

Fig. 1. Scanning ion conductance microscopy (SICM) imaging of rat ventricular myocyte. (A) Normal control ventricular myocyte. (B) Formamideinduced detubulated ventricular myocyte. Transmission: Optical transmission images of the cells with SICM scanning areas (red boxes, scale bars $=20 \mu \mathrm{m}$ ). 3D SICM: 3D SICM surface images are presented with an indication of Z-grooves (dotted yellow lines), crests (dotted blue lines), and surface T-tubule openings (red arrows). 2D SICM: In 2D SICM images, several lines were drawn on the $X$ - or $Y$ axis to get topographic line profiles of the surface images. Arrowheads indicate T-tubule openings. Line profiles: $X-Z$ axis line profiles of the lines (i) and (ii) show a regular appearance of Z-grooves and Ttubule openings along the longitudinal $X$-axis. The line profile of the line (iii) indicates Z-grooves without openings. Two arrowheads ( 1 and 2 ) present the traceable depth of the T-tubules. Line profiles (line iv and v) obtained from detubulated ventricle show a relatively flat surface and closed openings. FFT: Fast Fourier transformation (FFT) analysis of the control cell (line i) gives a peak of 1.88 $\mu \mathrm{m}$ of T-tubule intervals ( $n=48$ ). FFT of the line (iii) on a Z-groove has no peak. FFT of the detubulated cell surface (lines iv and $v$ ) has no regularity $(n=36)$. 


\section{RESULTS}

\section{Ventricular T-tubules and surface nanostructures}

For comparison, T-tubule structures of rat ventricular myocytes were imaged as a control cell. First, we compared the SICM cell surface images of normal control cells and formamideinduced detubulated myocytes. As shown in Fig. 1A, the distribution of T-tubule openings, Z-grooves, and crests were visualized from control myocytes. Along the longitudinal (or axial) direction of the myocyte, Z-grooves (yellow dotted line) and crests (blue dotted line) alternatively appeared and the height of the crest (or depth of the Z-groove) was $200 \mathrm{~nm}$ (Fig. 1A). At the nadir of the Z-grooves, regularly placed T-tubule openings (red arrow) were visualized (Fig. 1A). The SICM topographic line profiles and FFT peaks showed the presence of T-tubule openings at $1.88 \mu \mathrm{m}$ intervals along the longitudinal axis of the cell (Fig. 1A). On the contrary, the cell surface of the detubulated ventricular myocytes was relatively flat and regular Z-groove structures were severely disrupted (Fig. 1B). Sometimes, we could find a few numbers of T-tubule openings that were resistant to detubulation (arrowheads in Fig. 1B). SICM topographic line profiles showed flattened surface and the FFT function did not show any peaks, indicating that T-tubules openings and Z-grooves are profoundly disrupted in detubulated ventricular myocytes.

Since SICM surface images do not reveal the organization of intracellular T-tubules, we stained the live myocytes with a lipophilic membrane dye di-8-ANEPPS and visualized the T-
A

\section{Control}

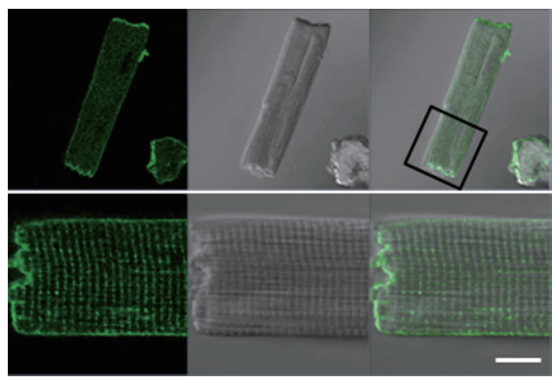

Y-Z
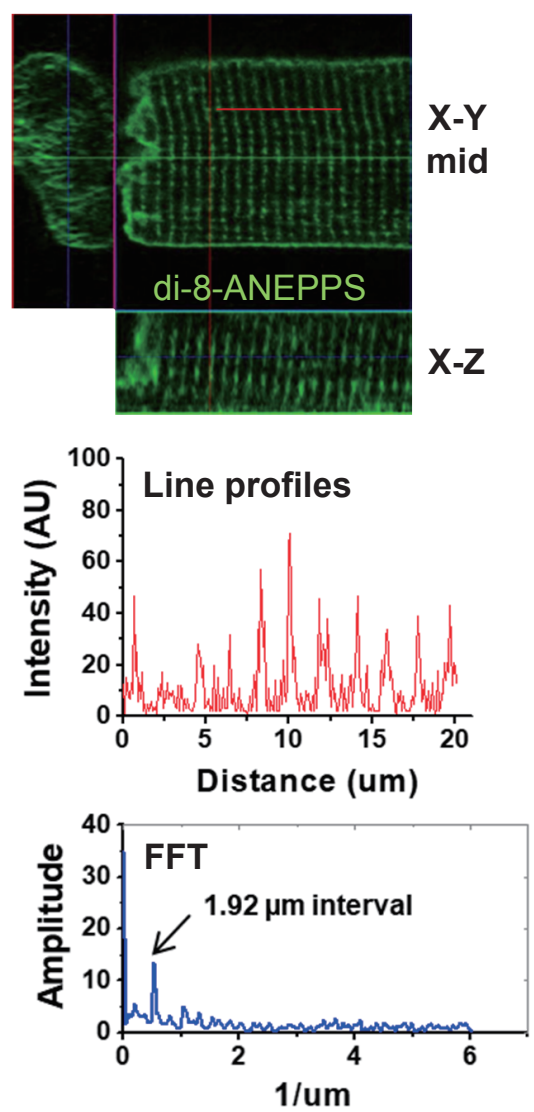

B
Detubulation
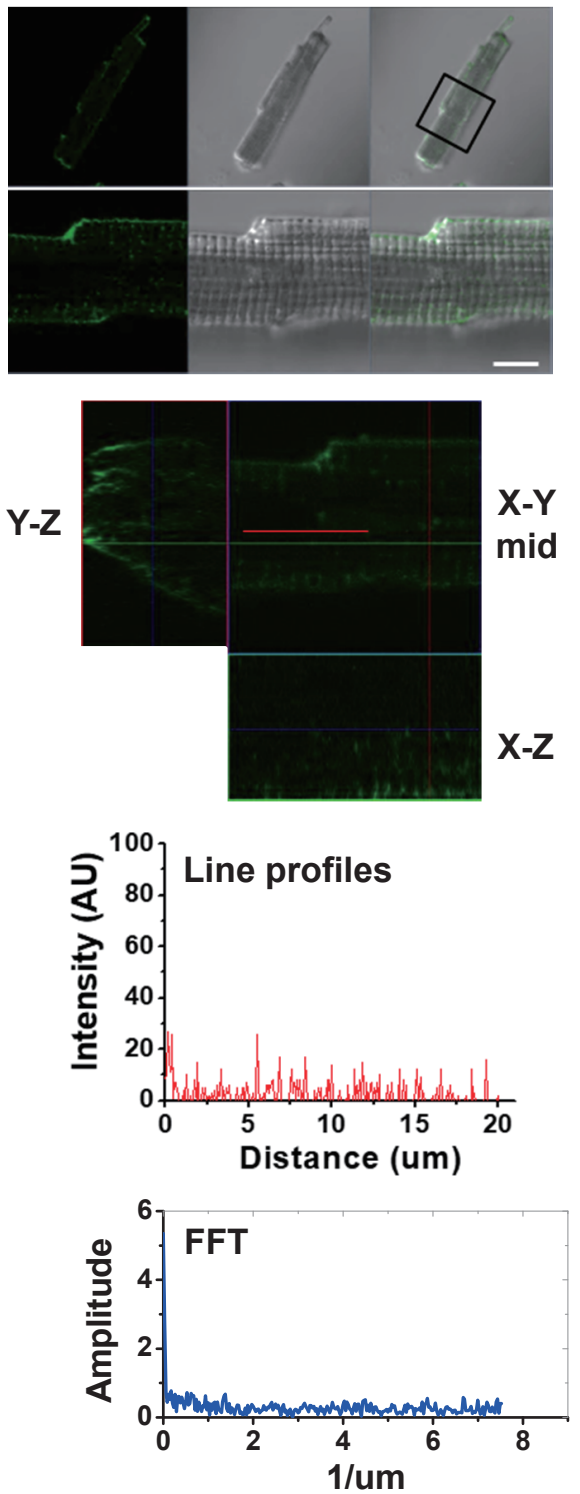

Fig. 2. Confocal imaging of the intracellular T-tubules of the ventricular myocyte. (A) Normal control myocyte. (B) Detubulated ventricular myocyte. A plane of di-8-ANEPPS confocal image (green) is overlaid with an optical transmission image of the cell (scale bar, $10 \mu \mathrm{m})$. Representative $X-Y, X-Z$, and $Y-Z$ confocal plane images are presented. Line profiles: The di-8-ANEPPS fluorescence intensity (arbitrary unit, $\mathrm{AU}$ ) profile on the longitudinal direction (solid red line in the $X-Y$ plane) shows regular striations of intracellular T-tubules. Fast Fourier transformation (FFT) of the fluorescence profile gives a peak of $1.92 \mu \mathrm{m}$ intervals $(n=16)$. (B) Confocal images of a detubulated ventricular myocyte. The di-8-ANEPPS image overlaid with transmission image, representative $X-Y, X-Z$, and $Y-Z$ confocal images, fluorescence intensity line profile, and FFT analysis are presented for detubulated myocyte. FFT of detubulated cell has no regular peaks $(n=11)$. 
tubule network under a confocal microscope. Fig. 2 compares the intracellular T-tubule network from control and detubulated ventricular myocytes. In control myocytes, regular T-tubule striations $(1.92 \mu \mathrm{m}$ intervals) were visualized on the $\mathrm{X}-\mathrm{Y}$ plane of the confocal images (Fig. 2A). In Fig. 2B, ventricular myocytes were stained with di-8-ANEPPS after formamide-induced detubulation. After detubulation, the cross striations of di-8-ANEPPS stained T-tubules were disappeared or faintly detected near the cell surface (Fig. 2B). FFT function of the fluorescence intensity profile showed no particular pattern or peaks in detubulated myocytes, suggesting that the formamide-induced detubulation protocol effectively dissect intracellular T-tubules from the cell surface membrane (Fig. 2B). Taken together, the results of Figs. 1 and 2 confirmed that the formamide-induced detubulation pro-
A

Smooth

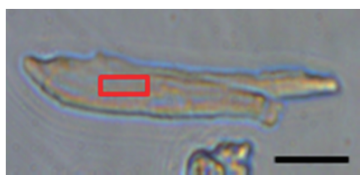

3D SICM

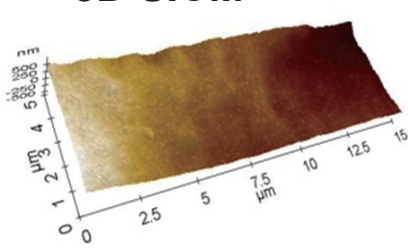

2D SICM
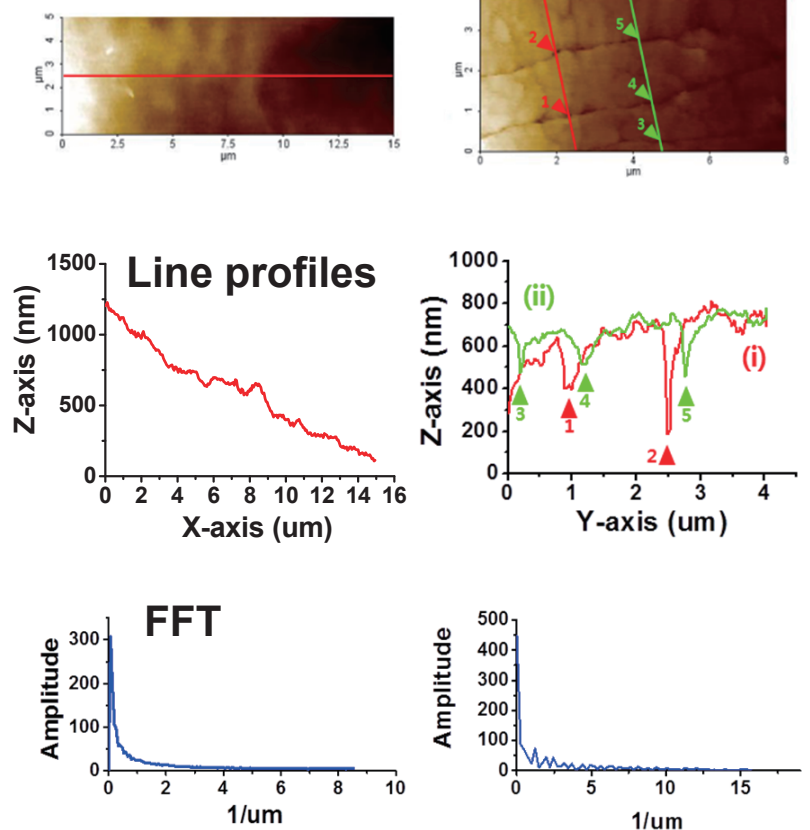

B
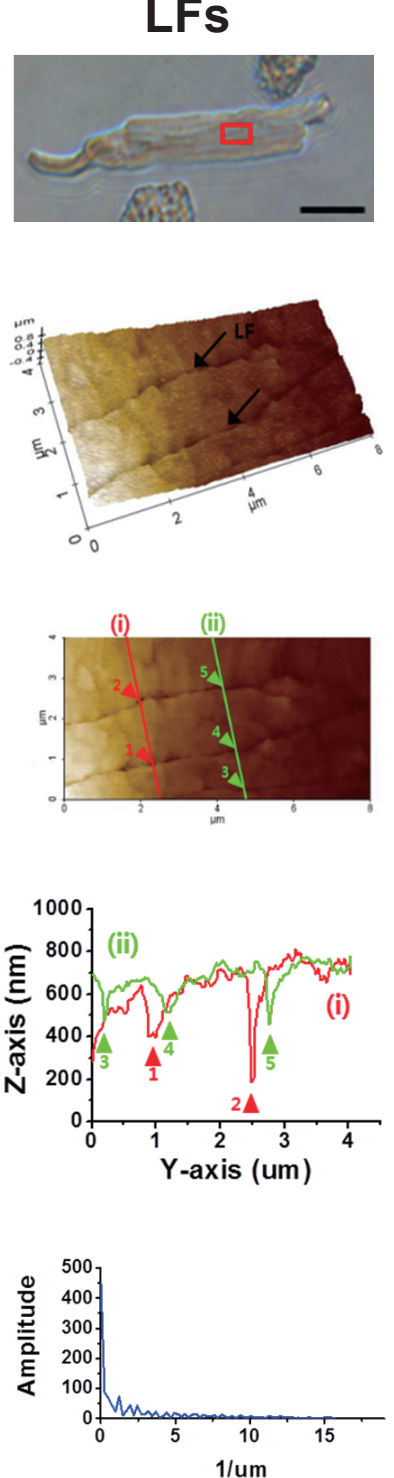

C

Vent
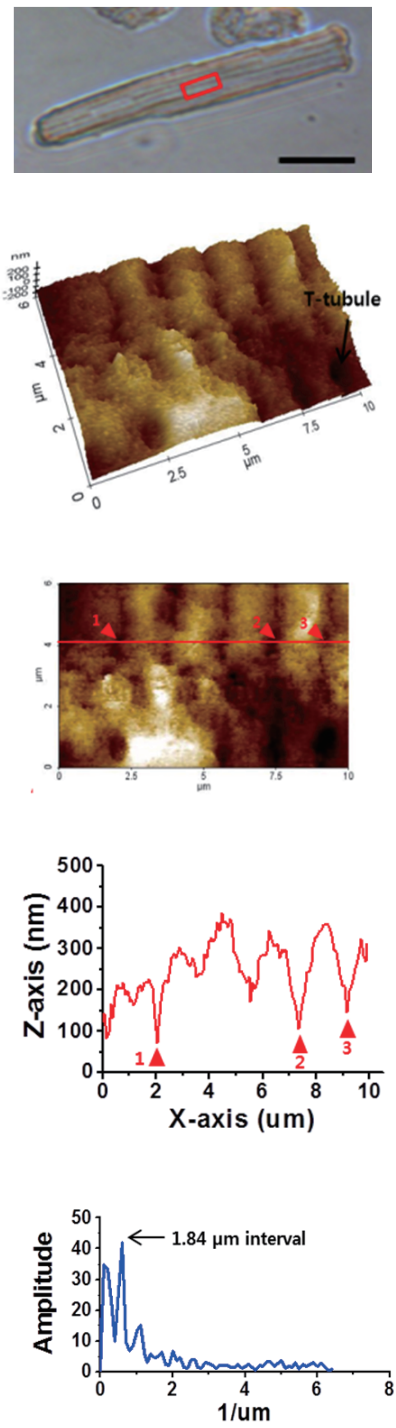

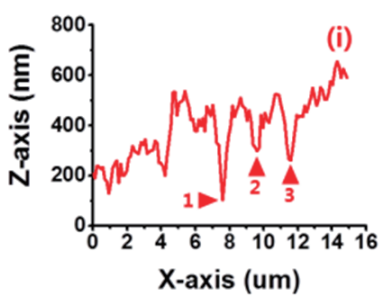

D

Mixed
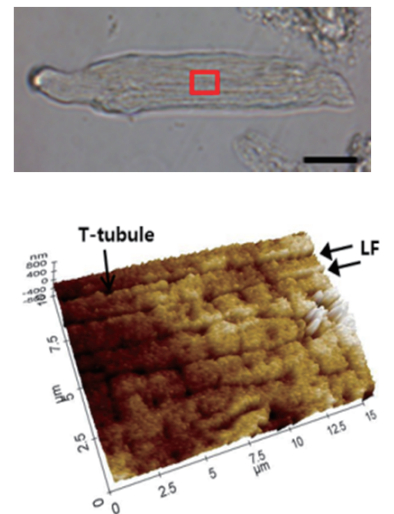

(ii)
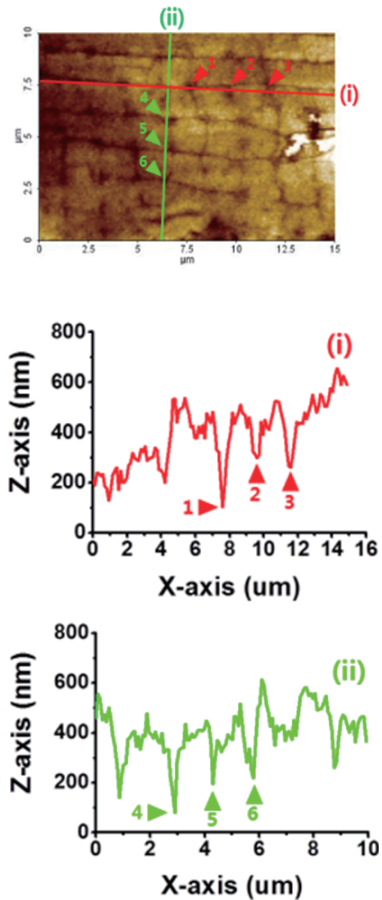

Fig. 3. Classification of rat atrial cell surface structure by scanning ion conductance microscopy (SICM) imaging. The 3D SICM and 2D SICM images, topographic line profiles, and Fast Fourier transformation (FFT) analyses are presented for each subtype (A: smooth-type, B: longitudinal fissures (LFs)-type, C: ventricular-type, and D: mixed-type). Optical transmission images (scale bar, $20 \mu \mathrm{m}$ ) are presented with the SICM scanning area (red boxes). The lines presented on each 2D SICM images are used for the construction of topographic line profiles and FFT analysis. FFT was not performed for mixed-type. (A) SICM images and topography of the smooth-type have no particular pattern or regularity. (B) SICM images of the LFs-type show two parallel running LFs (arrows). The arrowheads indicate multiple T-tubule openings inside LFs. FFT analysis (lines i and ii) gives no regularity. (C) SICM images of the ventricular-type show the Z-grooves and the T-tubule openings (arrowheads). FFT shows the T-tubules are regularly opened at 1.84 $\mu \mathrm{m}$ intervals. (D) SICM images of the mixed-type show multiple LFs and T-tubule openings (arrowheads in line i and ii). The average intervals between T-tubule openings (i.e., intervals between arrowheads in longitudinal line i) were $\sim 1.8 \mu \mathrm{m}$, though FFT has no regularity. 
cedure works effectively in rat ventricular myocytes.

\section{Classification of atrial cell surface structures and intracellular T-tubules}

Unlike ventricular myocyte, the surface structure of atrial myocyte that was observed by SICM imaging showed a great variety and complexity. Therefore, it was necessary to classify these surface structures into several categories. As classified in Fig. 3, atrial myocytes were divided into two main categories depending on the presence or absence of T-tubule openings, and then Ttubulated cells were reclassified into three types. As a result, we classified atrial cell surface structures into the following 4-subtypes; (i) 'smooth surface type (smooth-type)' that has smooth or flat cell surface with no T-tubule openings and Z-grooves, (ii) 'longitudinal fissures type (LFs-type)' that has a sulcus- or fissurelike structure that runs toward the longitudinal (or axial) axis of the cell length, (iii) 'ventricular-type' that has regular T-tubule openings and Z-grooves similar to the ventricular myocytes, and (iv) 'mixed type' that has a mixture of each subtype. Most of the mixed-type cells possessed both LFs-type and ventricular-type of structure in the same imaging area. The percent of each subtype was summarized as a pie chart in Fig. 7C (control cells), and detailed features of each subtype are as follows.

Fig. 3A shows a representative SICM image of smooth-type cells. About 38\% (58 of 153 cells) of atrial myocytes showed a smooth cell surface with no particular nanostructures. Their 3D and 2D SICM images showed no clear demarcation of Z-grooves and crests, and SICM line profiles and the FFT function revealed no particular patterns or peaks at any axis of the image (Fig. 3A).

Fig. 3B shows a representative SICM image of LFs-type cells. We found a novel, specialized membrane nanostructure in about $33 \%$ (50 of 153 cells) of atrial cells. The membrane folded into the cell, forming a fissure- or sulcus-like structure that spread out
A

Ventricular myocyte
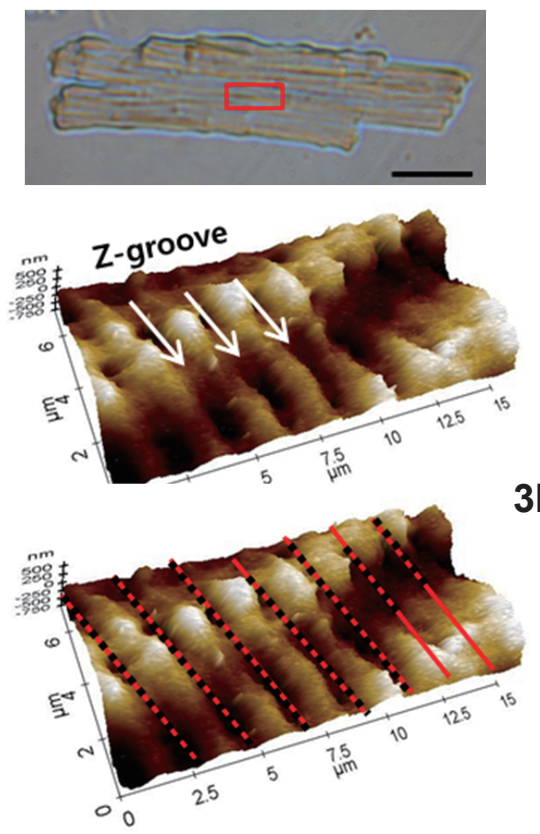

3D SICM

C

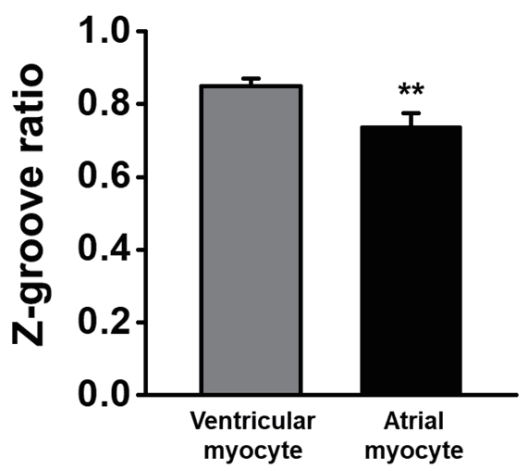

B

\section{Atrial myocyte}
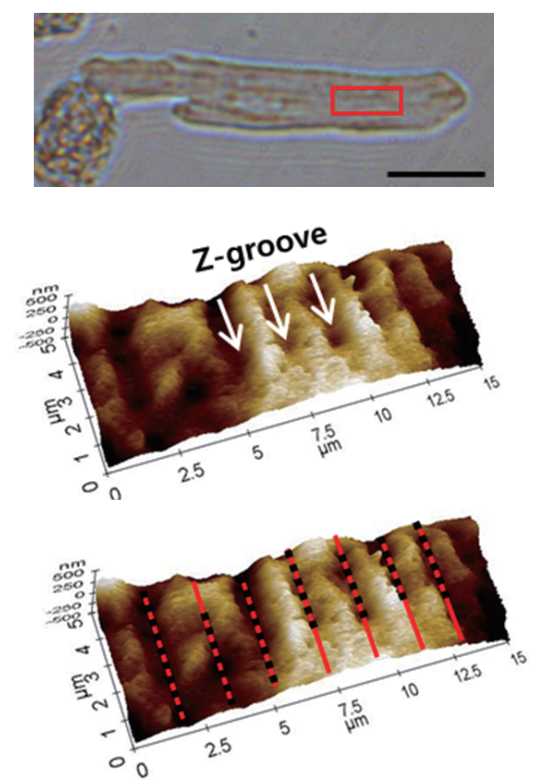

D

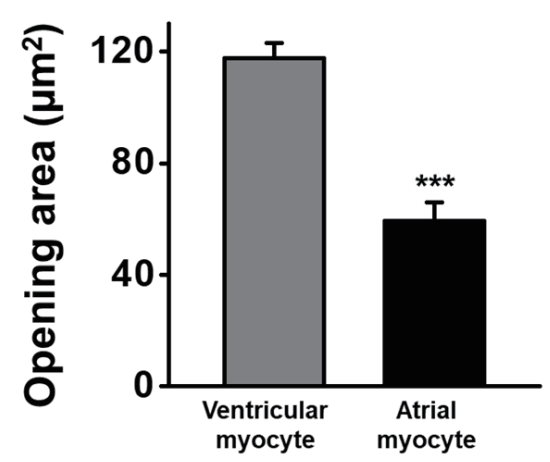

Fig. 4. Comparison of T-tubule openings between the ventricular myocyte and the ventricular-type of the atrial myocyte. (A) Ventricular myocyte. (B) Ventricular-type of atrial myocytes. The comparison of the Z-groove ratio (C) and T-tubule opening size (D) between the two cells. The Z-groove ratio was calculated from the ratio of the actual Z-groove (dotted lines) to the total extrapolated Z-grooves (sum of dotted and solid lines). The opening area $\left(\mu \mathrm{m}^{2}\right)$ was calculated from the measured diameter of the oval T-tubules orifice. ${ }^{* *} p<0.01$, *** $\mathrm{p}<0.005$. 
over the longitudinal axis of the cell length. Therefore, we named it a 'LFs'. Indeed, this structure is a special structure that has not been reported from any type of cardiac muscle cells. The opening width of the LFs ranged from 33 to $242 \mathrm{~nm}$, and the mean opening width was $114.87 \pm 2.17 \mathrm{~nm}$ ( $\mathrm{n}=284$ from 43 cells). The traceable depth of the LFs ranged from 31 to $1,133 \mathrm{~nm}$. The distance or interval between the LFs ranged from 0.37 to $2.7 \mu \mathrm{m}$. The 2D SICM line profiles (lines i and ii) showed $\sim 1.5 \mu \mathrm{m}$ distance between two parallel LFs (Fig. 3B). The line profile and FFT function obtained from the $\mathrm{X}$ or $\mathrm{Y}$ axis of the image did not have any regular pattern (Fig. 3B). The entire LFs images could be obtained by combining a series of SICM images taken from the whole area of a cell. These images revealed that LFs are not restricted in a specified region, but are found in entire of the cell. The LFs project relatively parallels and then merged or divided each other (data not shown). Therefore, it is difficult to define the LF network with a specified pattern. It is noteworthy that visible T-tubule openings were often found inside the LFs (arrowheads in Fig. 3B). Therefore, we postulated many T-tubules are branching out of the LF membrane. However, we could not define clearly the organization of T-tubules on the LF membrane because of the technical limitation of SICM, with which a probing pipette cannot penetrate deep inside the fissure.

About 17\% (26 of 153 cells) of atrial cells have regular T-tubule openings and Z-grooves that similar to the ventricular myocytes. Fig. 3C shows a representative SICM image of the ventriculartype cells. Like ventricular myocytes, ventricular-type atrial cells preserved well the Z-grooves and the crests. The 2D SICM line profile and its FFT function gave $\sim 1.84 \mu \mathrm{m}$ T-tubule opening intervals (Fig. 3C). To compare those of ventricular myocytes, we carefully measured the Z-groove ratio (or index) and T-tubule opening size of the atrial cells (Fig. 4). The Z-groove ratio indi-
A
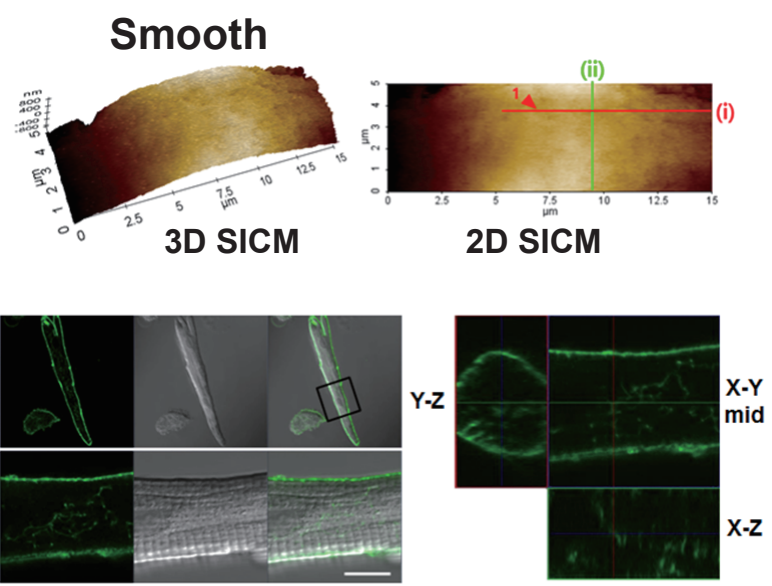

di-8-ANEPPS

C
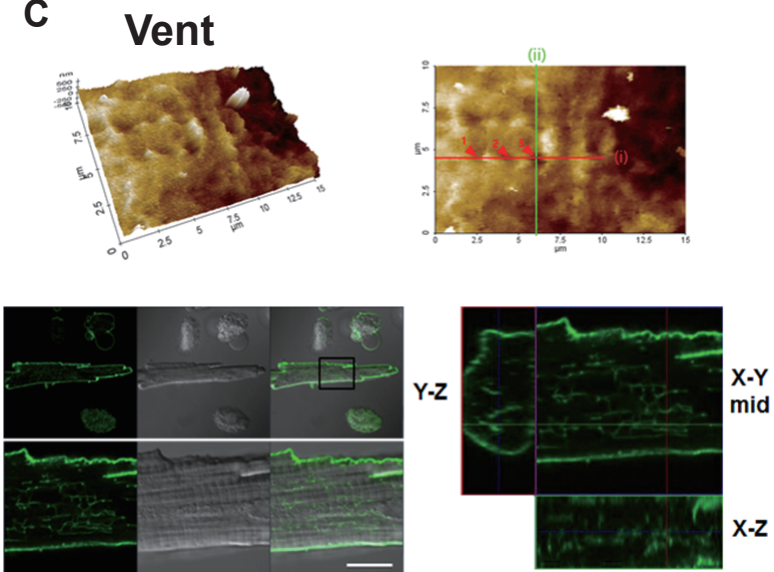

B
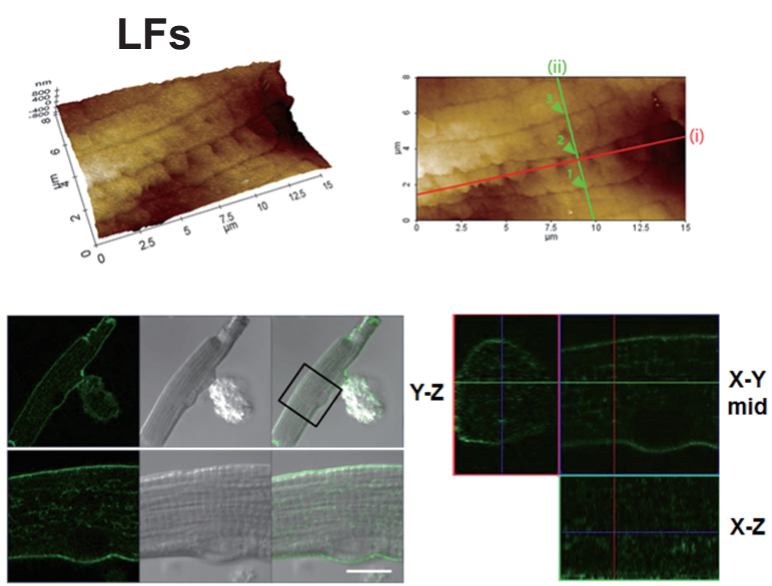

D
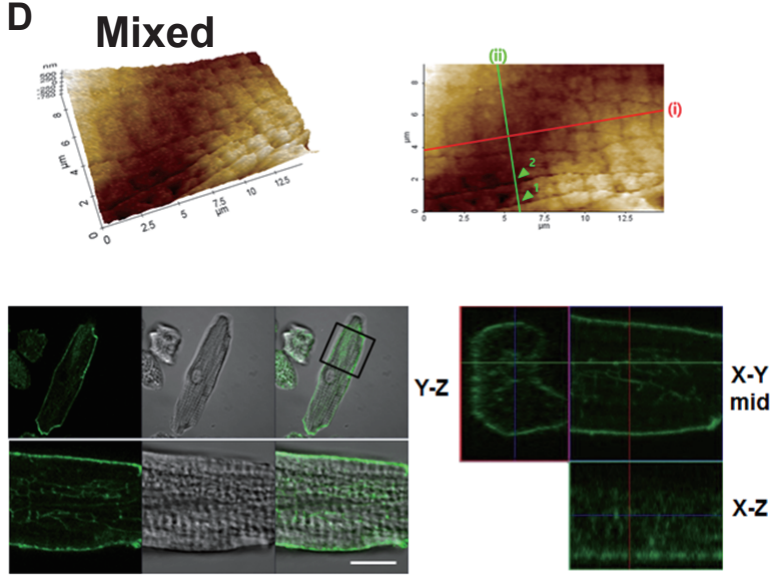

Fig. 5. Relationship between the atrial surface structure and the intracellular T-tubule networks. The 3D scanning ion conductance microscopy (SICM), 2D SICM, and confocal plane images obtained from each subtype are presented (A: smooth-type, B: longitudinal fissures (LFs)-type, C: ventricular-type, and D: mixed-type). Confocal images of intracellular T-tubules and the surface SICM images were recorded from the same cell. A plane of di8-ANEPPS confocal image (green) is overlaid with an optical transmission image, with an indication box of the scanning area (scale bar, $10 \mu \mathrm{m}$ ). The topographic line profiles are not presented in the figure. Arrowheads indicate the opening sites of T-tubules or LFs. Representative $X-Y, X-Z$, and $Y-Z$ confocal plane images are presented for each subtype. 
cates the ratio of actual to total extrapolated Z-grooves [4,22]. In Fig. $4 \mathrm{~A}$ and $\mathrm{B}$, the dotted lines over 3D SICM images indicate the length of Z-grooves with T-tubule openings, and the solid line represents the length without actual Z-grooves. Fig. $4 \mathrm{C}$ shows that the Z-groove ratio of the ventricular-type of atrial myocytes $(0.74 \pm 0.04, \mathrm{n}=20)$ is significantly lower than the ventricular myocytes $(0.85 \pm 0.02, \mathrm{n}=24, \mathrm{p}<0.01)$. Mostly, T-tubule openings have an oval shape. Therefore we calculated the $2 \mathrm{D}$ opening area $\left(\mu \mathrm{m}^{2}\right)$ with the measured diameters of the $\mathrm{X}$-axis and Y-axis. The diameters of ventricular T-tubule openings were $430 \pm 9$ (X-axis) and $342 \pm 11 \mathrm{~nm}$ (Y-axis) ( $\mathrm{n}=58$ from 11 cells). The diameters of ventricular-type atrial cells were $292 \pm 12$ (X-axis) and $241 \pm 16$ $\mathrm{nm}$ (Y-axis) ( $\mathrm{n}=30$ from 6 cells). In other words, atrial cells had $\sim 30 \%$ smaller T-tubule opening diameters than the ventricular myocytes. As a result, the calculated opening area of ventriculartype atrial cells $\left(59.1 \pm 6.8 \mu \mathrm{m}^{2}\right)$ was about half the ventricular Ttubules (117.5 $\pm 5.4 \mu \mathrm{m}^{2}, \mathrm{p}<0.001$; Fig. $\left.4 \mathrm{D}\right)$.

About $12 \%$ (19 of 153 cells) of atrial cells have a mixed surface of each subtype (mixed-type, Fig. 3D). In these cells, relatively regular T-tubule openings ( $\sim .8 \mu \mathrm{m}$ intervals) were located both inside and outside the LFs (see lines $i$ and ii in Fig. 3D). Although it is not shown here, a group of mixed-type cells had all three subtypes (LFs, regular T-tubule opening, and smooth surface).

\section{A}
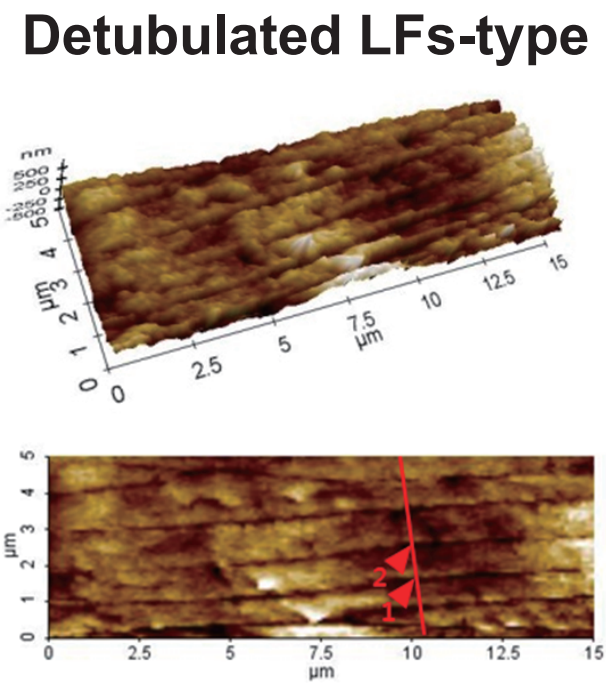

3D SICM
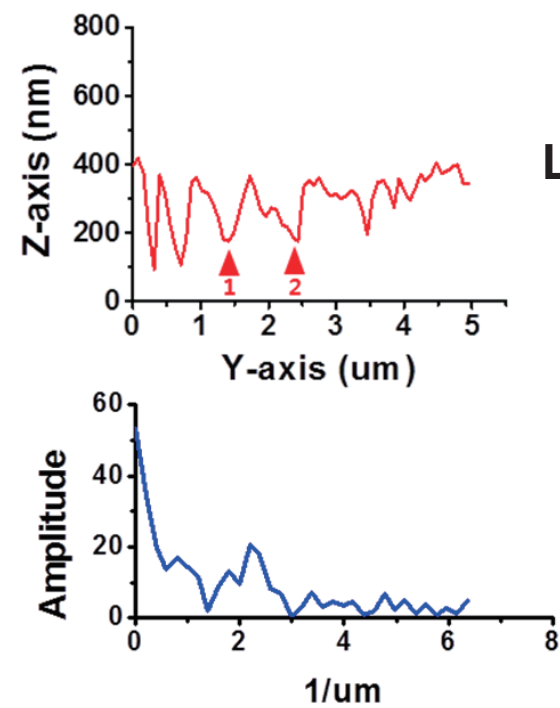

FFT
B

\section{Detubulated Vent-type}

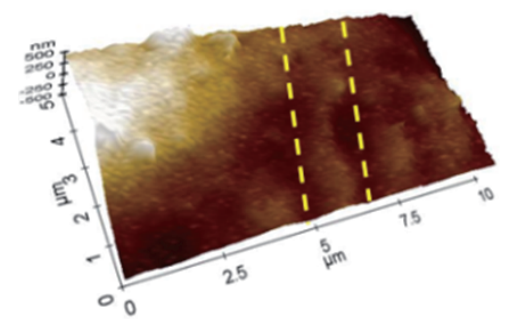

2D SICM
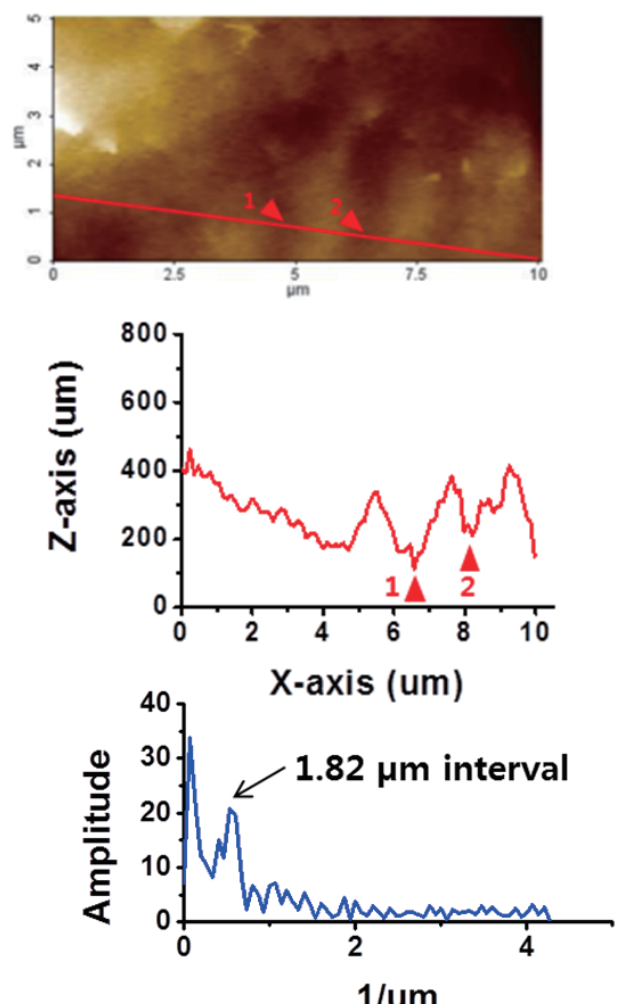

Fig. 6. Effect of formamide-induced detubulation on the structure of longitudinal fissures (LFs) and T-tubule openings. After formamide treatment of the cells, SICM images were obtained from the LFs-type (A) or the ventricular-type cells (B). The LFs remain intact after detubulation (A), but the T-tubule orifices are closed by detubulation in the ventricular-type (B). Arrowheads in each group indicate the LF openings and the Z-groove remnants, respectively. The line profile and Fast Fourier transformation (FFT) of the detubulated ventricular-type surface show regular positioning of Zgroove remnants at $\sim 1.8 \mu \mathrm{m}$ intervals $(\mathrm{n}=6)$. 


\section{Relationship between the intracellular T-tubule networks and the surface structures}

Correlation between the surface structures and the architecture of intracellular T-tubules was examined. We obtained confocal images of di-8-ANEPPS-stained intracellular T-tubules and surface SICM images from the same scanning areas of the cell. Technically, confocal imaging was taken first and then the cells were transferred into the SICM device to get the surface image. To do this, we marked the confocal imaged area and the physical orientation of the cell was carefully adjusted before taking SICM scanning.

Fig. 5A was taken from a smooth-type cell. The confocal images showed the cell preserved barely developed intracellular Ttubules. The presence of intracellular T-tubules in this cell was somewhat unexpected, but it could be explained by a few Ttubule openings that were sporadically and rarely observed from or out of the imaging area (an arrowhead in Fig. 5A; line profiles not shown). Fig. 5B shows intracellular T-tubules of the LFs-type cell. The cell showed an appreciable amount of reticular form of intracellular T-tubules. The surface SICM image showed parallel running LFs ( $2 \mu \mathrm{m}$ intervals), and several T-tubule openings
A
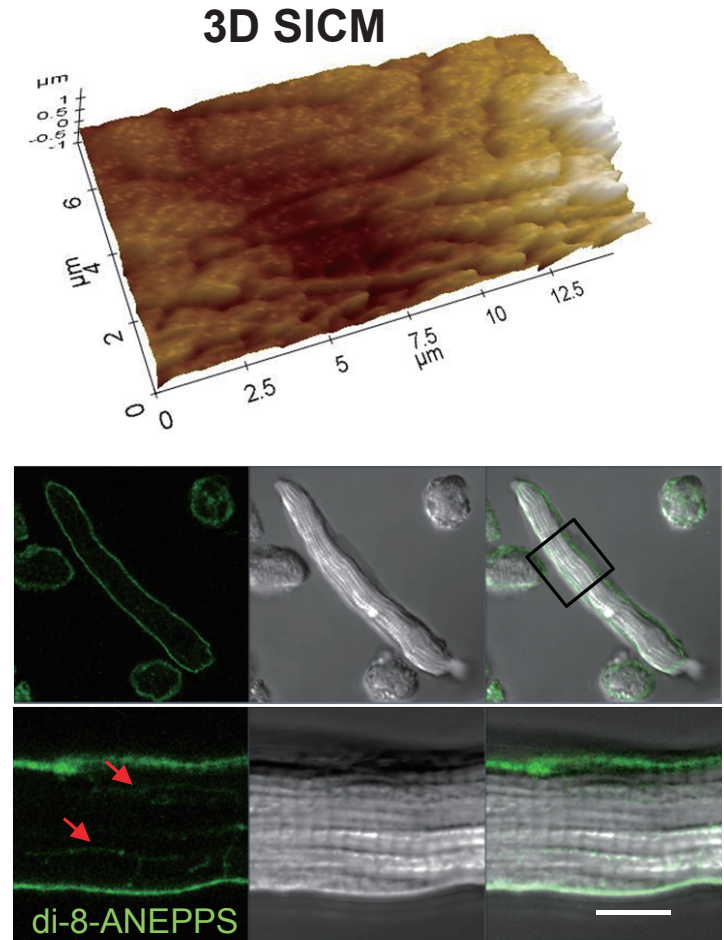

\section{D SICM}
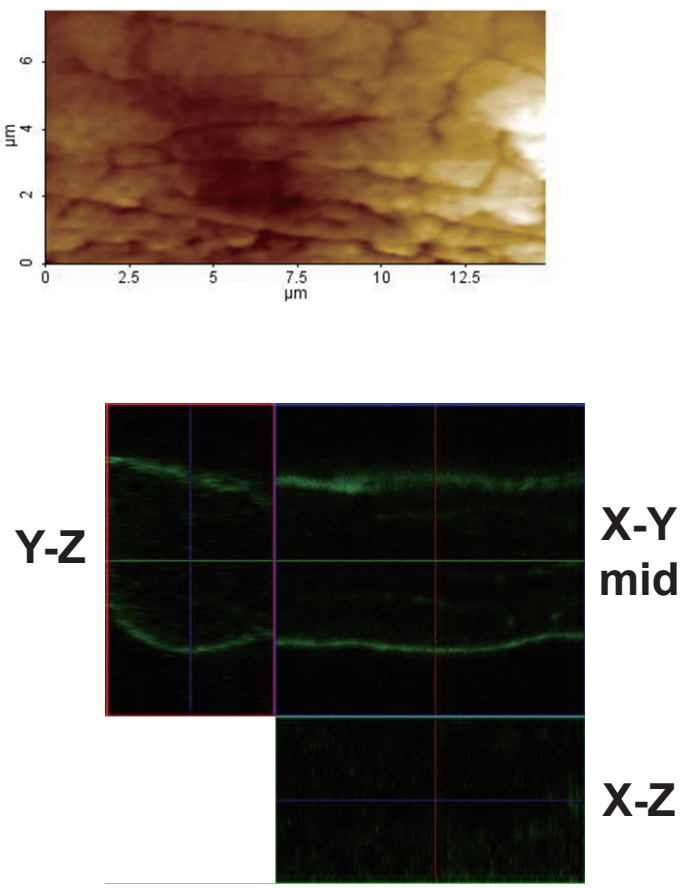

B

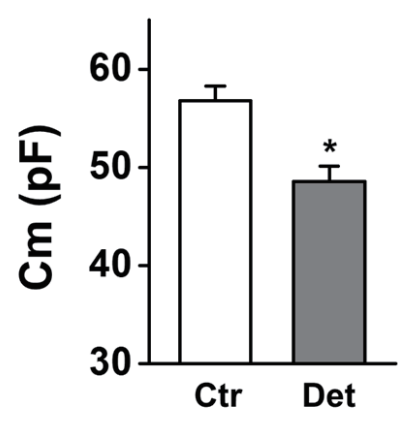

C

Control

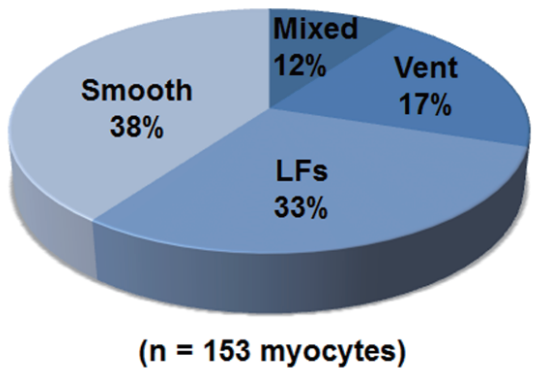

Detubulation

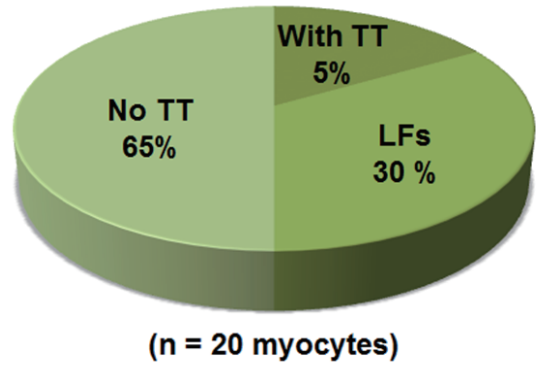

Fig. 7. Validation of formamide-induced detubulation in the atrial myocytes. (A) Atrial cells were stained with di-8-ANEPPS after formamide-induced detubulation procedure. Confocal and surface scanning ion conductance microscopy (SICM) images were taken from the same scanning areas of the cell. SICM images of the detubulated cell surface show the existence of longitudinal fissures (LFs). A plane of the di-8-ANEPPS confocal image is overlaid with an optical transmission image, with an indication box of the scanning area. Arrowheads in the confocal image indicate presumable LF membranes. Representative $X-Y, X-Z$, and $Y-Z$ confocal plane images are presented. (B) Detubulation reduced the cell membrane capacitance $\left({ }^{*} p<\right.$ 0.05). (C) Proportions of each subtype, classified by SICM surface structure, are compared between control and detubulation cells. 
were found inside the LFs (arrowheads in line ii of Fig. 5B; line profiles not shown). Fig. 5C shows intracellular T-tubules in a ventricular-type cell, where a relatively well-developed intracellular T-tubules were found as a reticular arrangement. Although T-tubule openings (arrowheads in line i) and Z-grooves (line ii) were partially disrupted in the course of the experiment, their regular positioning at $\sim 1.89 \mu \mathrm{m}$ intervals confirmed the cell was ventricular-type (Fig. 5C). Fig. 5D shows images of a mixed-type cell. Similar to LFs- or ventricular-type cells, a relatively well developing reticular T-tubule network was imaged from the cell. The surface SICM image showed a mixed presence of parallel LFs and T-tubule openings at $\sim 1.85 \mu \mathrm{m}$ intervals (arrowheads in line ii; line profiles not shown). Taken together, reticular forms of intracellular T-tubules were found in LFs-, ventricular-, and mixed- type cells, but barely developing T-tubules were found in smoothtype cells.

\section{Effects of detubulation on the atrial T-tubules and surface nanostructures}

The structural disorganization of T-tubule systems was investigated in detubulated atrial myocytes. As a representative sample, SICM images obtained from formamide-treated LFs- and ventricular-type cells are presented in Fig. 6. First of all, it is noteworthy that LFs are very resistant to detubulation protocol (Fig. 6A). After detubulation, only a slight deformation of LFs was observed and the overall LFs integrity remained the same. Although the opening width of the formamide-treated LFs was wider than non-

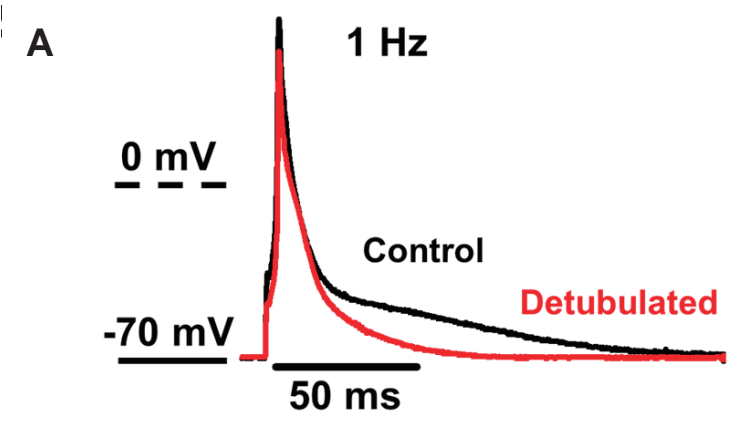

B

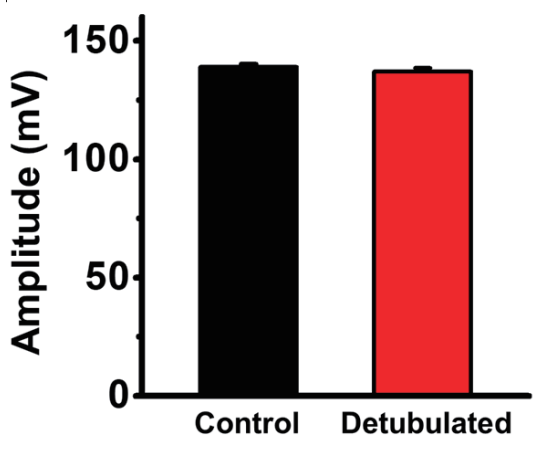

D
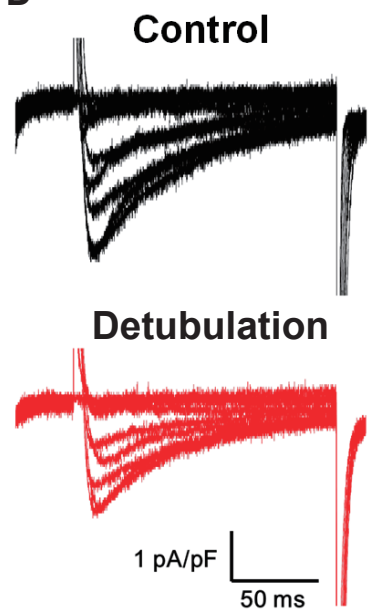

C

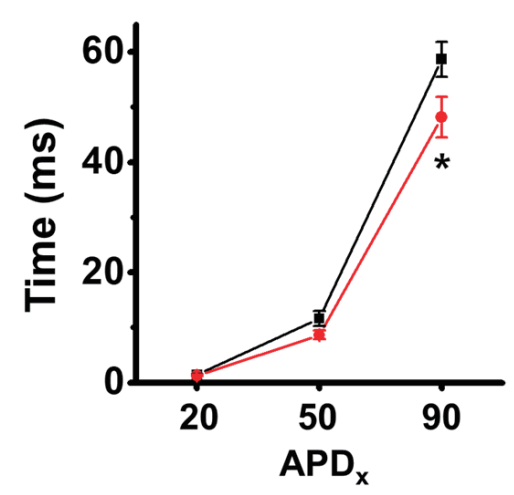

E

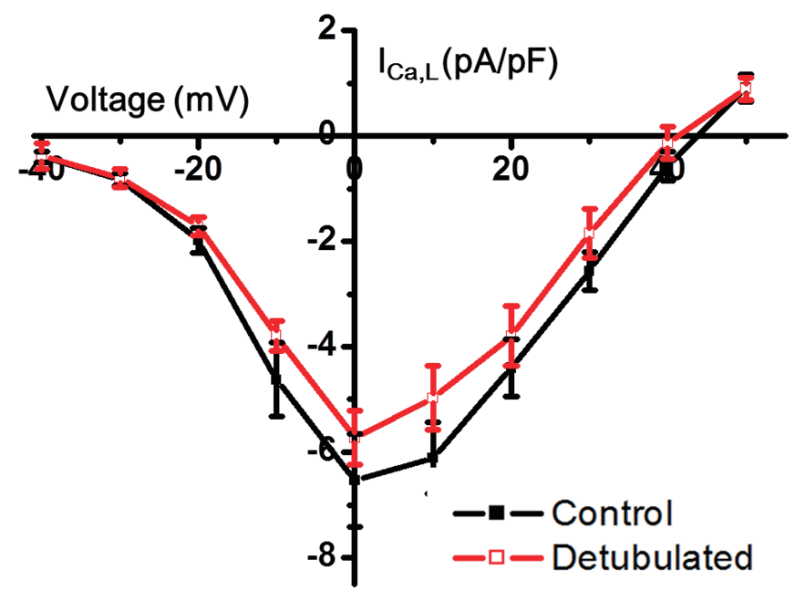

Fig. 8. The change of atrial action potential and L-type $\mathrm{Ca}^{2+}$ channel (LTCC) current by detubulation. (A) The representative trace shows the shortening of atrial action potential (AP) by detubulation. (B) AP amplitudes are not changed by detubulation. (C) Change of action potential duration (APD) ${ }_{20}, \mathrm{APD}_{50}$, and $\mathrm{APD}_{90}$ by detubulation ( ${ }^{*} \mathrm{p}<0.05$ ). Representative LTCC traces (D) and I-V curves $(\mathrm{E})$ show the reduction of LTCC by detubulation. 
treated control cells $(165.4 \pm 4.9 \mathrm{~nm}$ in detubulation vs. $114.9 \pm 2.2$ $\mathrm{nm}$ in control, $\mathrm{p}<0.001$ ), the traceable LFs depth was not greatly changed by detubulation $(159.3 \pm 7.6 \mathrm{~nm}$ in detubulation vs. 158.5 $\pm 7.0 \mathrm{~nm}$ in control). Most of the T-tube openings located inside the LF were considered to be disappeared by detubulation (arrowheads in Fig. 6A), which was confirmed by confocal images in Fig. 7A. On the contrary, detubulation almost completely removed Ttubule openings from the surface of ventricular-type cells (Fig. 6B). Although the cell surface has become slightly flat, the FFT function of a longitudinal SICM line profile gives a peak of 1.82 $\mu \mathrm{m}$ intervals, which is an indicator of Z-groove remnants (arrowheads in Fig. 6B).

The formamide-induced disconnection between the surface openings and intracellular T-tubule network (i.e., detubulation), was further confirmed in Fig. 7. Atrial cells were treated first with formamide, and then the cells were stained with di-8-ANEPPS for confocal imaging of intracellular T-tubules. After obtaining confocal images, the same cells were transferred to a SICM device to get surface change. An example of a formamide-treated mixed-type cell is provided in Fig. 7A. After detubulation, most internal di-8-ANEPPS fluorescence was not visible and only a few horizontal lines remained (Fig. 7A). We estimate these horizontal lines are LF membranes that penetrated deep into the cell (arrows in Fig. 7A). The SICM image obtained from the same cell showed the LFs remained intact on the deformed cell surface.
The formamide-induced detubulation was further confirmed by decreased cell membrane capacitance (Fig. 7B). Detubulation decreased the cell membrane capacitance to $85.6 \%(48.6 \pm 1.6 \mathrm{pF}$, $\mathrm{n}=24)$ of the control cells (56.8 $\pm 1.5 \mathrm{pF}, \mathrm{n}=32, \mathrm{p}<0.05)$. The results indicate that, on average, the T-tubule membrane accounts for $\sim 14 \%$ of the total cell membrane area.

We classified detubulated cell surface into 3 groups; (i) 'no T-tubules' that have no surface T-tubule openings, (ii) 'with T-tubules' that have a countable number of surface T-tubule openings, and (iii) 'LFs' that have surface LFs in the absence or presence of T-tubule openings. The percent of each group was summarized as a pie chart in Fig. 7C (detubulation). About 65\% (13 of 20 cells) of cells were classified into 'no T-tubules', $30 \%$ (6 of 20 cells) into 'LFs', and $~ 5 \%$ ( 1 of 20 cells) into 'with T-tubule'. The proportion of 'no T-tubules' cells (65\%) corresponded to the sum of smooth-type (38\%) and ventricular-type (26\%) in control cells. Importantly, the proportion of LFs-type was not changed by detubulation (33\% in control vs. $30 \%$ in detubulation). These results confirmed that surface T-tubule openings, but not LFs, were effectively removed by formamide-induced detubulation protocol in atrial myocytes.
A
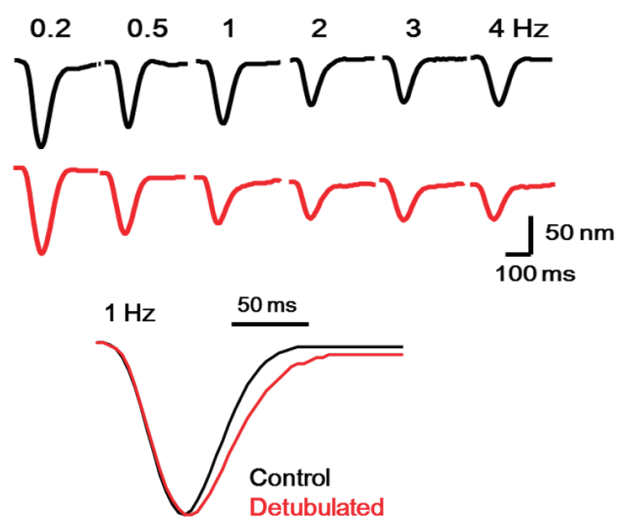

C

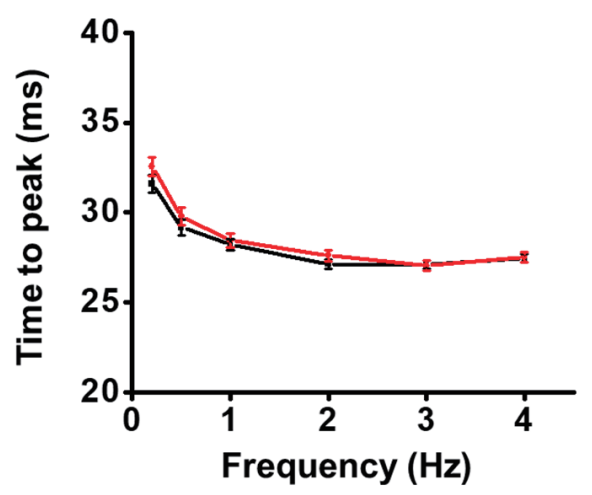

B

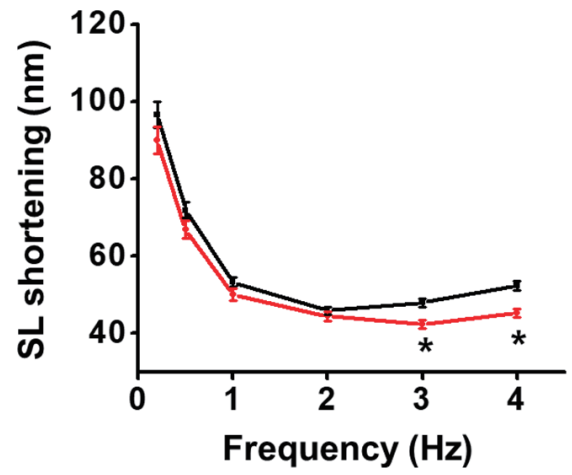

D

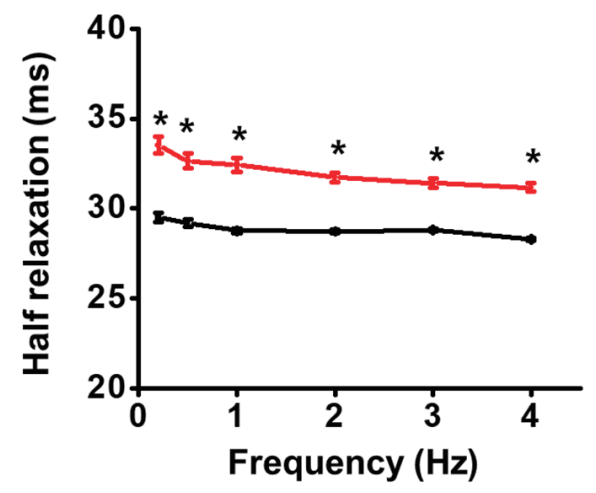

Fig. 9. The change of atrial myocyte contraction by detubulation. (A) Representative contraction traces that evoked by varying electric field stimulation (EFS) frequencies. Sarcomere length (SL) shortening traces recorded at $1 \mathrm{~Hz}$ are overlaid to compare the change of contraction kinetics. (B) The decrease of SL shortening by detubulation. (C) Systolic time was not changed by detubulation. (D) At every frequency of EFS, half-relaxation time was significantly prolonged by detubulation. Control $(n=$ 47). Detubulation $(n=48) .{ }^{*} p<0.05$. 


\section{Effects of detubulation on the atrial excitation- contraction coupling}

Detubulation effect on the atrial AP was recorded by currentclamp recording (Fig. 8A). At $1 \mathrm{~Hz}$ frequency of recording, AP amplitude was not changed by detubulation (Fig. 8B). Detubulation resulted in statistically significant shortening of $\mathrm{APD}_{90}(58.7$ $\pm 3.2 \mathrm{~ms}$ in control vs. $48.1 \pm 3.7 \mathrm{~ms}$ in detubulation, $\mathrm{p}<0.05$ ), but $\mathrm{APD}_{20}$ and $\mathrm{APD}_{50}$ were not greatly changed (Fig. 8C).

L-type $\mathrm{Ca}^{2+}$ channels (LTCCs) are embedded highly on the T-tubule membrane, especially in the ventricular cells, to trigger synchronized $\mathrm{Ca}^{2+}$-induced $\mathrm{Ca}^{2+}$ release. Fig. $8 \mathrm{E}$ shows that detubulation reduced LTCCs density $(\mathrm{pA} / \mathrm{pF})$. Therefore, the decrease of LTCC density by detubulation indicates that T-tubule membranes possess higher LTCC density than the cell surface membrane (i.e., the outside of the T-tubule membrane or the membrane where Z-grooves and crests are placed). In further experiments, the LTCC density ratio between the T-tubule membrane and surface sarcolemma needs to be calculated.

Finally, we tested whether removal of T-tubules affects atrial myocytes' contractile properties. The isolated atrial myocytes were paced by increasing frequency of EFS, and the contraction behavior was analyzed. Compared to the control, the shortening length of the atrial sarcomere (SL) tended to decrease between 0.2 to $2 \mathrm{~Hz}$ EFS, and significant reduction was observed at 3 and $4 \mathrm{~Hz}$ stimulation (Fig. 9A, B; p < 0.05). The time to peak contraction (i.e., systolic time) was not changed by detubulation (Fig. 9C). However, a delayed relaxation, which is calculated by half relaxation time, was observed at every frequency of EFS stimulation (Fig. 9D). The results suggested the removal of T-tubules disturbs the EC-coupling of atrial myocytes.

\section{DISCUSSION}

By SICM and confocal imaging of the live rat atrial myocytes, we confirmed the diversity of cell surface structures and the Ttubules system. We found at least $60 \%$ of rat atrial myocytes have appreciable amounts of T-tubules (Figs. 5 and 7C). Because of the complex cell surface structure, we needed to divide the cells into four subtypes depending on the presence of T-tubule openings or LFs (i.e., smooth-type, LFs-type, ventricular-type, and mixedtype). About $38 \%$ of the atrial cells were smooth-type, $33 \%$ were LFs-type, $17 \%$ were ventricular-type, and $12 \%$ were mixed-type (Fig. 3C). In a recent SICM study with rat atrial myocytes, the cell surface structure was divided into 'organized', 'disorganized', and 'no surface structure' [23]. Among those, 'no surface structure' corresponds to 'smooth-type' in our study, and the 'organized' and 'disorganized surface' resembled 'ventricular-type' myocytes that have distinct T-tubule openings on the Z-grooves. However, the previous study presented the Z-groove index but they did not provide additional information about the T-tubule open- ing size or the proportion of each cell group [23]. Therefore, it is noteworthy that our study provides comprehensive information about surface nanostructure, including T-tubule opening size and Z-groove ratio, along with the proportion of each cell group (Figs. 3 and 4). Moreover, it is highly valuable that our research discovered a novel membrane structure that we named LFs and accurately identified the correlation between surface structure and intracellular T-tubule network (Fig. 5).

We have identified that the LFs-, ventricular-, and mixed-type cells have a reticular T-tubule network. By contrast, smooth type cells have very few surface openings and intracellular T-tubules (Fig. 5). Since the absence of intracellular T-tubules does not support the rapid propagation of the action potential to produce homogenous systolic $\mathrm{Ca}^{2+}$ rise, it is reasonable to explain the ECcoupling process of smooth-type cells by a classical centripetal $\mathrm{Ca}^{2+}$ wave theory [7-9]. Nevertheless, the fact that about $60 \%$ of atrial cells have distinct intracellular T-tubules network means that centripetal $\mathrm{Ca}^{2+}$ wave theory cannot fully explain the ECcoupling process that occurred in each myocyte. Therefore, it is necessary to establish a new EC-coupling mechanism based on heterogeneous T-tubule development.

In ventricular myocyte, the T-tubule membrane contains highly expressed LTCC ( $80 \%$ of the total LTCC) and NCX and juxtapose RyRs on the SR to produce synchronized systolic $\mathrm{Ca}^{2+}$ transient and diastolic $\mathrm{Ca}^{2+}$ extrusion $[8,24,25]$. Our imaging studies of ventricular myocytes (Figs. 1 and 2) show that surface T-tubule openings are regularly arranged and intracellular T-tubules existed as regular vertical striations as previously shown in other studies $[9,14,24,26]$. By contrast, ventricular-type atrial cells have a low Z-groove index and narrow T-tubule openings (Fig. 4). A low Z-groove index means a low density of T-tubule openings. In this type of cell, the T-tubules begin to opens regularly on the surface of Z-grooves, but only a loosely connected reticular Ttubule network has been found inside the cell (Fig. 5C). In terms of the connection between surface openings and intracellular Ttubules, the LFs- or mixed-type exhibit a qualitatively similar pattern to the ventricular-type cells (Figs. 5B and D). For this reason, we assume that these immature T-tubules are in the early stage of T-tubule development and maturation. If this assumption is valid, most of the T-tubule openings observed on the atrial cell surface will be immature ones and their penetration depth will be very limited. Therefore, the correlation between the maturity of the atrial muscles and the development of the T-tubules needs to be validated. Simply, a study on the age-dependent maturation of atrial T-tubules will answer this question.

In about one-third of atrial cells, we found a novel membrane structure named LFs. The LFs are projected longitudinally to the length of the cell and run parallel to each other at irregular distances (Fig. 3B). The discovery of multiple T-tubule openings inside the LFs indicates that the T-tubules are diverging from the LF membrane. Another interesting finding is that LFs are highly resistant to formamide-induced detubulation procedure. As 
shown in Fig. 6A, most of the LFs remain intact after detubulation. This property makes it difficult to determine the physiological function of the LFs. The structure-function relationship of the LFs would be an important issue in future studies. Especially, the role of the LF membrane during $\mathrm{Ca}^{2+}$ propagation needs to be investigated. Currently, we hypothesize that the LF membrane accompanying multiple T-tubules can bring $\mathrm{Ca}^{2+}$ into the center of the cell. If this assumption is valid, a rapid $\mathrm{Ca}^{2+}$ explosion occurs at around the LF wall, or at the deep center of the cell, resulting in $\mathrm{Ca}^{2+}$ propagation to the cell periphery. In atrial myocytes, a functional or immunolocalization study showed that close association between RyR and LTCC appears only at the cell periphery, resulting in atrial cell-specific centripetal $\mathrm{Ca}^{2+}$ signals [12]. Under rapid confocal microscopy, atrial myocytes showed multiple $\mathrm{Ca}^{2+}$ sparks around the edge of the cell (i.e., cell periphery) immediately after membrane depolarization, with no $\mathrm{Ca}^{2+}$ response at the deep center of the cell. This consequently induces a centripetal propagation of $\mathrm{Ca}^{2+}$ waves and delayed central $\mathrm{Ca}^{2+}$ increase, thus it induces a U-shaped $\mathrm{Ca}^{2+}$ transient. Therefore, the $\mathrm{U}$-shaped $\mathrm{Ca}^{2+}$ transient is regarded as the $\mathrm{Ca}^{2+}$ response that occurred in atrial cells with no T-tubules (i.e., smooth-type cells) [7]. Some experiments have shown that heterogeneously distributed T-tubules in atrial myocytes cause systolic $\mathrm{Ca}^{2+}$ to be initiated simultaneously at the cell periphery and center of the cell. This synchronized $\mathrm{Ca}^{2+}$ transient has been classified as a W-shaped $\mathrm{Ca}^{2+}$ transient. Based on our findings of LFs, it can be suggested that LFs provide sites for the initiation of central $\mathrm{Ca}^{2+}$ transient that generates the Wshaped $\mathrm{Ca}^{2+}$ transient.

The relationship between T-tubule disorganization and heart diseases has been observed. In animal heart failure models, loss of T-tubules and consequent decoupling between EC couplons (LTCC, NCX, RyRs, and SERCA) were suggested as a causative factor for impaired EC-coupling and reduced contractility of the heart $[4,25,27]$. The loss of T-tubules has been also demonstrated in ventricular myocytes of failing human heart [4]. Therefore, the in vitro detubulation model has been widely used to evaluate the role of T-tubules in cardiac EC-coupling or to simulate T-tubule disorder heart diseases. In the present study, we used the formamide-induced detubulation method to see whether disrupted T-tubules alter the atrial EC-coupling. Confocal imaging and cell capacitance measurement confirmed the formamide treatment effectively removed rat atrial T-tubules (Fig. 7). Detubulation resulted in a shortening of $\mathrm{APD}_{50}$ and $\mathrm{APD}_{90}$, which is explained in part by the decreased LTCC current (Fig. 8). Detubulation attenuated myocyte contraction and caused delayed relaxation (Fig. 9). These observations can be explained by impaired $\mathrm{Ca}^{2+}$ kinetics due to the loss of T-tubules. The T-tubule membrane contains both $\mathrm{Ca}^{2+}$ providing LTCC and $\mathrm{Ca}^{2+}$ removal NCX. As a result, the removal of $\mathrm{T}$-tubules produces smaller $\mathrm{Ca}^{2+}$ transient, which decays more slowly than the normal cells having NCX on the Ttubules. Our results demonstrate that T-tubules are important to maintaining normal EC-coupling of the atrial myocytes, though the cells have a rudimentary T-tubule system. Unlike our study, however, previous studies reported that formamide-induced detubulation of atrial myocytes did not change the cell membrane capacitance, $\mathrm{Ca}^{2+}$ current amplitude, action potential configuration, and the $\mathrm{Ca}^{2+}$ transient or the response of the $\mathrm{Ca}^{2+}$ transient to isoprenaline $[12,28]$. Therefore, it is necessary to clarify whether these differences are caused by an inaccurate assessment of the Ttubule development. In the future study, it will be very important to determine whether disrupted or disorganized T-tubules causes or aggravates atrial diseases such as atrial arrhythmias.

\section{ACKNOWLEDGEMENTS}

This work was supported by the National Research Foundation of Korea (NRF) Grant funded by the Korean Government (MSIP) (2016R1D1A1B03934748).

\section{CONFLICT OF INTEREST}

The authors declare no conflicts of interest.

\section{REFERENCES}

1. Cheng H, Cannell MB, Lederer WJ. Propagation of excitationcontraction coupling into ventricular myocytes. Pflugers Arch. 1994;428:415-417.

2. Bers DM. Cardiac excitation-contraction coupling. Nature. 2002; 415:198-205.

3. Yang Z, Pascarel C, Steele DS, Komukai K, Brette F, Orchard CH. $\mathrm{Na}^{+}-\mathrm{Ca}^{2+}$ exchange activity is localized in the T-tubules of rat ventricular myocytes. Circ Res. 2002;91:315-322.

4. Lyon AR, MacLeod KT, Zhang Y, Garcia E, Kanda GK, Lab MJ, Korchev YE, Harding SE, Gorelik J. Loss of T-tubules and other changes to surface topography in ventricular myocytes from failing human and rat heart. Proc Natl Acad Sci U S A. 2009;106:68546859.

5. Wei S, Guo A, Chen B, Kutschke W, Xie YP, Zimmerman K, Weiss $\mathrm{RM}$, Anderson ME, Cheng H, Song LS. T-tubule remodeling during transition from hypertrophy to heart failure. Circ Res. 2010;107:520531.

6. Heinzel FR, Bito V, Biesmans L, Wu M, Detre E, von Wegner F, Claus P, Dymarkowski S, Maes F, Bogaert J, Rademakers F, D'hooge J, Sipido K. Remodeling of T-tubules and reduced synchrony of $\mathrm{Ca}^{2+}$ release in myocytes from chronically ischemic myocardium. Circ Res. 2008;102:338-346.

7. Kirk MM, Izu LT, Chen-Izu Y, McCulle SL, Wier WG, Balke CW, Shorofsky SR. Role of the transverse-axial tubule system in generating calcium sparks and calcium transients in rat atrial myocytes. $J$ Physiol. 2003;547(Pt 2):441-451.

8. Bootman MD, Smyrnias I, Thul R, Coombes S, Roderick HL. Atrial cardiomyocyte calcium signalling. Biochim Biophys Acta. 2011; 1813:922-934. 
9. Dibb KM, Clarke JD, Eisner DA, Richards MA, Trafford AW. A functional role for transverse ( $\mathrm{t}-$ ) tubules in the atria. J Mol Cell Cardiol. 2013;58:84-91.

10. Frisk M, Koivumäki JT, Norseng PA, Maleckar MM, Sejersted OM, Louch WE. Variable t-tubule organization and $\mathrm{Ca}^{2+}$ homeostasis across the atria. Am J Physiol Heart Circ Physiol. 2014;307:H609H620.

11. Richards MA, Clarke JD, Saravanan P, Voigt N, Dobrev D, Eisner DA, Trafford AW, Dibb KM. Transverse tubules are a common feature in large mammalian atrial myocytes including human. Am J Physiol Heart Circ Physiol. 2011;301:H1996-H2005.

12. Brette F, Komukai K, Orchard CH. Validation of formamide as a detubulation agent in isolated rat cardiac cells. Am J Physiol Heart Circ Physiol. 2002;283:H1720-H1728.

13. Ziman AP, Gómez-Viquez NL, Bloch RJ, Lederer WJ. Excitationcontraction coupling changes during postnatal cardiac development. J Mol Cell Cardiol. 2010;48:379-386.

14. Smyrnias I, Mair W, Harzheim D, Walker SA, Roderick HL, Bootman MD. Comparison of the T-tubule system in adult rat ventricular and atrial myocytes, and its role in excitation-contraction coupling and inotropic stimulation. Cell Calcium. 2010;47:210-223.

15. Anariba F, Anh JH, Jung GE, Cho NJ, Cho SJ. Biophysical applications of scanning ion conductance microscopy (SICM). Mod Phys Lett B. 2012;26:1130003.

16. Novak P, Li C, Shevchuk AI, Stepanyan R, Caldwell M, Hughes S, Smart TG, Gorelik J, Ostanin VP, Lab MJ, Moss GW, Frolenkov GI, Klenerman D, Korchev YE. Nanoscale live-cell imaging using hopping probe ion conductance microscopy. Nat Methods. 2009;6:279281.

17. Chen CC, Zhou Y, Baker LA. Scanning ion conductance microscopy. Annu Rev Anal Chem (Palo Alto Calif). 2012;5:207-228.

18. Miragoli M, Moshkov A, Novak P, Shevchuk A, Nikolaev VO, ElHamamsy I, Potter CM, Wright P, Kadir SH, Lyon AR, Mitchell JA, Chester AH, Klenerman D, Lab MJ, Korchev YE, Harding SE, Gorelik J. Scanning ion conductance microscopy: a convergent high-resolution technology for multi-parametric analysis of living cardiovascular cells. J R Soc Interface. 2011;8:913-925.

19. Klenerman D, Korchev YE, Davis SJ. Imaging and characterisation of the surface of live cells. Curr Opin Chem Biol. 2011;15:696-703.

20. Liu BC, Lu XY, Song X, Lei KY, Alli AA, Bao HF, Eaton DC, Ma HP. Scanning ion conductance microscopy: a nanotechnology for biological studies in live cells. Front Physiol. 2013;3:483.

21. Kawai M, Hussain M, Orchard CH. Excitation-contraction coupling in rat ventricular myocytes after formamide-induced detubulation. Am J Physiol. 1999;277:H603-H609.

22. Gorelik J, Yang LQ, Zhang Y, Lab M, Korchev Y, Harding SE. A novel Z-groove index characterizing myocardial surface structure. Cardiovasc Res. 2006;72:422-429.

23. Glukhov AV, Balycheva M, Sanchez-Alonso JL, Ilkan Z, AlvarezLaviada A, Bhogal N, Diakonov I, Schobesberger S, Sikkel MB, Bhargava A, Faggian G, Punjabi PP, Houser SR, Gorelik J. Direct evidence for microdomain-specific localization and remodeling of functional L-type calcium channels in rat and human atrial myocytes. Circulation. 2015;132:2372-2384.

24. Brette F, Sallé L, Orchard CH. Quantification of calcium entry at the T-tubules and surface membrane in rat ventricular myocytes. Biophys J. 2006;90:381-389.

25. Ibrahim M, Gorelik J, Yacoub MH, Terracciano CM. The structure and function of cardiac t-tubules in health and disease. Proc Biol Sci. 2011;278:2714-2723.

26. Soeller C, Cannell MB. Examination of the transverse tubular system in living cardiac rat myocytes by 2-photon microscopy and digital image-processing techniques. Circ Res. 1999;84:266-275.

27. Swift F, Franzini-Armstrong C, Øyehaug L, Enger UH, Andersson KB, Christensen G, Sejersted OM, Louch WE. Extreme sarcoplasmic reticulum volume loss and compensatory T-tubule remodeling after Serca2 knockout. Proc Natl Acad Sci U S A. 2012;109:39974001.

28. Brette F, Sallé L, Orchard CH. Differential modulation of L-type $\mathrm{Ca}^{2+}$ current by SR Ca ${ }^{2+}$ release at the T-tubules and surface membrane of rat ventricular myocytes. Circ Res. 2004;95:e1-e7. 